\title{
Terminology as a key uncertainty in net land use and land cover change carbon flux estimates
}

\author{
J. Pongratz ${ }^{1}$, C. H. Reick ${ }^{1}$, R. A. Houghton ${ }^{2}$, and J. I. House ${ }^{3}$ \\ ${ }^{1}$ Max Planck Institute for Meteorology, Hamburg, Germany \\ ${ }^{2}$ Woods Hole Research Center, Falmouth, MA, USA \\ ${ }^{3}$ Cabot Institute \& Department of Geography, University of Bristol, Bristol, UK
}

Correspondence to: J. Pongratz (julia.pongratz@mpimet.mpg.de)

Received: 22 July 2013 - Published in Earth Syst. Dynam. Discuss.: 7 August 2013

Revised: 30 January 2014 - Accepted: 11 February 2014 - Published: 27 March 2014

\begin{abstract}
Reasons for the large uncertainty in land use and land cover change (LULCC) emissions go beyond recognized issues related to the available data on land cover change and the fact that model simulations rely on a simplified and incomplete description of the complexity of biological and LULCC processes. The large range across published LULCC emission estimates is also fundamentally driven by the fact that the net LULCC flux is defined and calculated in different ways across models. We introduce a conceptual framework that allows us to compare the different types of models and simulation setups used to derive land use fluxes. We find that published studies are based on at least nine different definitions of the net LULCC flux. Many multi-model syntheses lack a clear agreement on definition. Our analysis reveals three key processes that are accounted for in different ways: the land use feedback, the loss of additional sink capacity, and legacy (regrowth and decomposition) fluxes. We show that these terminological differences, alone, explain differences between published net LULCC flux estimates that are of the same order as the published estimates themselves. This has consequences for quantifications of the residual terrestrial sink: the spread in estimates caused by terminological differences is conveyed to those of the residual sink. Furthermore, the application of inconsistent definitions of net LULCC flux and residual sink has led to double-counting of fluxes in the past. While the decision to use a specific definition of the net LULCC flux will depend on the scientific application and potential political considerations, our analysis shows that the uncertainty of the net LULCC flux can be substantially reduced when the existing terminological confusion is resolved.
\end{abstract}

\section{Introduction}

Future climate change and the required strength of our mitigation efforts depend strongly on the terrestrial emissions and sinks. The change in the atmospheric carbon content $\left(C_{\text {atmos }}\right)$ due to anthropogenic activity is determined by the emissions from fossil-fuel burning $\left(F_{\text {fossil }}\right)$ and the net exchange fluxes between atmosphere and ocean $\left(F_{\text {ocean-atmos }}\right)$ and between atmosphere and land ( $\left.F_{\text {land-atmos }}\right)$. Currently, the terrestrial biosphere is a net sink for carbon with 1.4 $\mathrm{GtC} \mathrm{yr}^{-1}$ uptake over the 2000s (Le Quéré et al., 2013a). This flux $F_{\text {land-atmos }}$ - also called the "net biosphere flux", "net land flux", or "net land-atmosphere flux" - is the result of two opposing fluxes, the "net land use and land cover change flux" ( $\left.F_{\text {LULCC }}\right)$ and the "residual terrestrial flux" $\left(F_{\text {residual }}\right)$. The global carbon budget can thus be formulated as

$$
\begin{aligned}
\frac{\mathrm{d} C_{\mathrm{atmos}}}{\mathrm{d} t} & =F_{\text {fossil }}-F_{\text {ocean-atmos }}-F_{\text {land-atmos }} \\
& =F_{\text {fossil }}-F_{\text {ocean-atmos }}+F_{\text {LULCC }}-F_{\text {residual }},
\end{aligned}
$$

where fluxes $F_{\text {fossil }}$ and $F_{\text {LULCC }}$ are defined as positive into the atmosphere, and fluxes $F_{\text {ocean-atmos }}, F_{\text {land-atmos }}$, and $F_{\text {residual }}$ as positive out of the atmosphere.

For centuries, human activities have released carbon to the atmosphere through conversion and management of land (referred to in many different ways in the published literature, e.g. "land use and land cover change", LULCC; "land use, land use change and forestry", LULUCF; or simply "land use change", LUC) (e.g. Pongratz et al., 2009b; Reick et al., 2010; Stocker et al., 2011; IPCC, 2006). These losses of carbon from land ( $F_{L U L C C}$ in Eq. 1) are referred to as "net land 
use flux" or "net LULCC flux". The term "net" is added because LULCC causes not just emissions to the atmosphere (e.g. when a forest is cleared, or harvested wood products are burnt or decay), but also uptake of $\mathrm{CO}_{2}$ from the atmosphere (e.g. from growth of planted or recovering vegetation following anthropogenic disturbance). The net LULCC flux is of the order of $1.0 \pm 0.5 \mathrm{GtC} \mathrm{yr}^{-1}$ (Le Quéré et al., 2013a), with a range across 13 different model results (each with specific definitions explained later) compiled in the meta-analysis of Houghton et al. (2012) of 0.8 to $1.5 \mathrm{PgC} \mathrm{yr}^{-1}$ for the 1990s.

The difference between the net biosphere flux and net LULCC flux implies a sink, typically known as the "residual terrestrial flux" ( $F_{\text {residual }}$ in Eq. 1$)$ as it is calculated as the residual of other more directly estimated terms in the carbon budget (i.e. fossil-fuel and LULCC emissions minus atmospheric growth and ocean uptake). This sink amounts to $2.4 \pm 0.8 \mathrm{GtC} \mathrm{yr}^{-1}$ uptake over the 2000s (Le Quéré et al., 2013a) and is corroborated by inventories in intact forests (e.g. Pan et al., 2011). It is thought to be primarily due to the indirect effects of anthropogenic environmental change on terrestrial ecosystems: the fertilizing effects of rising $\mathrm{CO}_{2}$ in the atmosphere, changes in nutrient cycles, and climate change impacts (Zaehle et al., 2011; Le Quéré et al., 2013a; Piao et al., 2013). The indirect effects of environmental change affect both managed and unmanaged (pristine) land. As will be shown in this article, the indirect effects are accounted for to very different extents and in very different ways in published estimates of the net LULCC flux. This is partly due to the political or scientific purpose for which a methodology is employed, but is often also constrained by the nature of available data or modelling tools.

The net LULCC flux is the most uncertain of the directly estimated terms in the global carbon budget, and this uncertainty propagates into estimating the residual flux. Since the net LULCC flux is not directly observable on the global scale, models are an essential tool to estimate it. However, model differences induce a major uncertainty in net LULCC flux estimates: of the 13 studies on LULCC emissions in Houghton et al. (2012), and five in Le Quéré et al. (2013a), the underlying model estimates differed particularly with respect to the assumed rates of deforestation (partly but not entirely dependent on driving data), the carbon densities for vegetation cleared, and the inclusiveness of management activities. Some of these uncertainties may be reduced in the future due to increasing data availability: for example, estimates of biomass can be derived from observations, which recently have become available on a spatially explicit basis for large regions of the world (Baccini et al., 2012); however, they are still subject to considerable uncertainty and will not be available for the pre-satellite era. In addition, processbased models simulate vegetation biomass as a prognostic variable and as such depend on simplification and parameterization of various processes. Differences due to input data and processes included in models have been described and sometimes quantified and account for about $50 \%$ uncertainty in LULCC estimates (Houghton et al., 2012).

However, published estimates contain another source of uncertainty: terminological differences that result from differences in definition of which flux component to include in the net LULCC flux. These differences result from ad hoc choices in the simulation setup, but are partly predetermined by the type of model used.

Estimates stem from three generations of models, which each simulate the $\mathrm{CO}_{2}$ exchange between biosphere and atmosphere in different ways:

a. Bookkeeping models track changes in the carbon stocks of the areas undergoing LULCC using growth and decay curves of soil and vegetation carbon of predefined shape. In the original bookkeeping approach (e.g. Houghton et al., 1983) carbon densities are based on inventories and do not respond to transient changes in $\mathrm{CO}_{2}$ and climate. Later approaches (e.g. Gitz and Ciais, 2003) include a modification factor to the growth curves depending on the atmospheric $\mathrm{CO}_{2}$ concentration to account in a simplified form for the effects of environmental changes on carbon stocks.

b. Dynamic global vegetation models (DGVMs) simulate soil and plant processes, and their response to external $\mathrm{CO}_{2}$ and climate drivers. These environmental conditions are prescribed from data externally and the simulations are thus uncoupled. This means that environmental conditions are not altered by the biospheric activity within the model setup.

c. Earth system models (ESMs) link process-based vegetation models such as DGVMs interactively with carbon cycle and climate modelling and account for climate- and $\mathrm{CO}_{2}$-mediated feedbacks that could not be represented in uncoupled DGVM simulations: for example, land use change emits $\mathrm{CO}_{2}$ and causes biogeophysical changes in albedo and latent heat flux; these biogeochemical and biogeophysical changes affect climate and $\mathrm{CO}_{2}$ concentrations, which in turn feed back on growth and decomposition rates; this in turn affects the net LULCC flux, closing the feedback loop.

Independent of the type of model used, the net LULCC flux is determined with respect to a reference state that excludes changes in land use or land cover; i.e. the net LULCC flux $F_{\text {LULCC }}$ is defined as difference

$F_{\text {LULCC }}=\Phi_{\text {LULCC }}-\Phi_{\text {noLULCC }}$,

where $\Phi_{\text {LULCC }}$ and $\Phi_{\text {noLULCC }}$ denote the net biosphere flux ( $F_{\text {land-atmos }}$ in Eq. 1$)$ in a simulation with $\left(\Phi_{\text {LULCC }}\right)$ and without LULCC disturbance $\left(\Phi_{\text {noLULCC }}\right)$. We acknowledge that the reference state may not always be simulated explicitly 
in a separate simulation; in particular in cases where environmental conditions are assumed to not change over the course of the LULCC simulation the initial state of carbon stocks and fluxes in the LULCC simulation may serve as an implicit reference. It is also possible to quantify individual flux components, such as instantaneous LULCC emissions, without an explicit reference. However, the without-LULCC reference is crucially needed, implicitly or explicitly, to answer the question of LULCC impact as compared to a world that had not seen such human disturbance. Yet the assumed reference state differs between studies, including the vegetation cover, carbon density and environmental drivers. We will show below how different estimates for the net LULCC flux differ by the assumed reference $\Phi_{\text {noLULCC }}$.

To compare the terminology across published net LULCC flux estimates, we introduce a conceptual framework suitable for distinguishing the different methods. Others (Strassmann et al., 2008; Gasser and Ciais, 2013) have also developed conceptual frameworks to derive flux components for LULCC-induced carbon fluxes, but focus on selected concepts and consider only a subset of relevant flux components. By contrast, our study aims to give a comprehensive comparison of the various methods used in published estimates. While these previous studies provided mathematical formulations that allow for actual quantifications of various fluxes, our study aims at a comprehensive, illustrative framework that allows the reader to understand how published estimates of the net LULCC flux differ in terms of their definition due to the specific type of model and model setup used to derive them.

Terminological differences have increased the uncertainty range across estimates of the net LULCC flux unnecessarily, because they can be resolved more easily than intrinsic uncertainties in data availability, process understanding, and model parameterizations. More and more climate models as well as economic and trade models have been extended to include LULCC over the past years, and new approaches of quantifying carbon stocks and fluxes directly using data on LULCC and biomass from remote sensing are being developed (Baccini et al., 2012; Harris et al., 2012). To be able to consistently compare past and forthcoming estimates of the net LULCC flux, confusion about terminological issues should be resolved.

\section{Materials and methods}

\subsection{Framework for partitioning the net LULCC flux}

The aim of our framework is to break down the various published estimates of the net LULCC flux into the same flux components. This allows for a direct comparison of which flux components are included and excluded by the various published estimates. Our framework for comparison distinguishes between land carbon fluxes induced by the direct effects of anthropogenic LULCC activity ("direct" referring to LULCC-induced changes in vegetation distribution); carbon fluxes induced by the effects of human-induced environmental changes, which are an indirect result of LULCC or other anthropogenic activity; and fluxes that arise due to the combination of direct LULCC effects and indirect effects mediated by environmental changes.

Carbon fluxes from direct LULCC effects involve different timescales. Methodological approaches typically distinguish between "instantaneous emissions" to the atmosphere upon a human intervention like land-clearing fires (termed " $I$ "; see Table 1 for list of abbreviations), and "legacy fluxes" (" $L$ ") from the readjustment of the carbon stocks to the new type of vegetation and/or type and intensity of management over time. Legacy fluxes include respiration of plant residues (e.g. harvest slash, dead roots) and disturbed soil organic matter, changes in the stocks of products such as paper and timber, and recovery of the living carbon stocks. The legacy flux thus comprises sources and sinks. In sustainably managed forests with a harvest regrowth cycle, these gross sources and sinks may be large, but they are of the same order of magnitude over time and thus result in a small net flux (Pan et al., 2011; Houghton et al., 2012). The distinction between instantaneous emissions and legacy flux differs between methods to some extent: instantaneous emissions may refer to emissions at the instance of LULCC (e.g. Pongratz et al., 2009b) or all emissions within a year (Houghton et al., 2012). Many of the methods discussed below quantify both fluxes together. However, it is necessary to keep the two fluxes separate in our framework; it will illustrate that the instantaneous emissions are the only flux always accounted for, while the legacy emissions are partly omitted by some model approaches. Note that for satellite and some inventory-databased approaches, the time period of analysis is shorter than the timescale of legacy effects, so that legacy emissions may be partially omitted, or all emissions may be assumed to be instantaneous (e.g. DeFries et al., 2002; Harris et al., 2012; IPCC, 2006; FAO, 2013).

Underlying all processes involved in the legacy flux is a disequilibrium between carbon uptake and loss. For an ecosystem, this disequilibrium is caused by a mismatch of net primary productivity (NPP) and heterotrophic respiration $\left(R_{\mathrm{h}}\right)$. Calling NEP $=\mathrm{NPP}-R_{\mathrm{h}}$ net ecosystem productivity, $\mathrm{NEP} \neq 0$ is the signature of disequilibrium. The direct effects of LULCC cause a disequilibrium between NPP and $R_{\mathrm{h}}$ that often lasts decades to centuries, but without further disturbance systems tend to recover from this imbalance. An equilibrium may also be reached in managed systems if on average the amount of carbon that is extracted from the ecosystem is balanced by regrowth, as for example in sustainable forestry.

A NPP- $R_{\mathrm{h}}$ disequilibrium may be induced not only by direct LULCC effects, but also by any change in environmental conditions (we denote carbon fluxes due to environmental changes by " $E$ "). This happens because NPP and $R_{\mathrm{h}}$ react in 
Table 1. Carbon stocks and fluxes used in our conceptual framework for comparison of published studies. See Table 2 for meaning of subscripts.

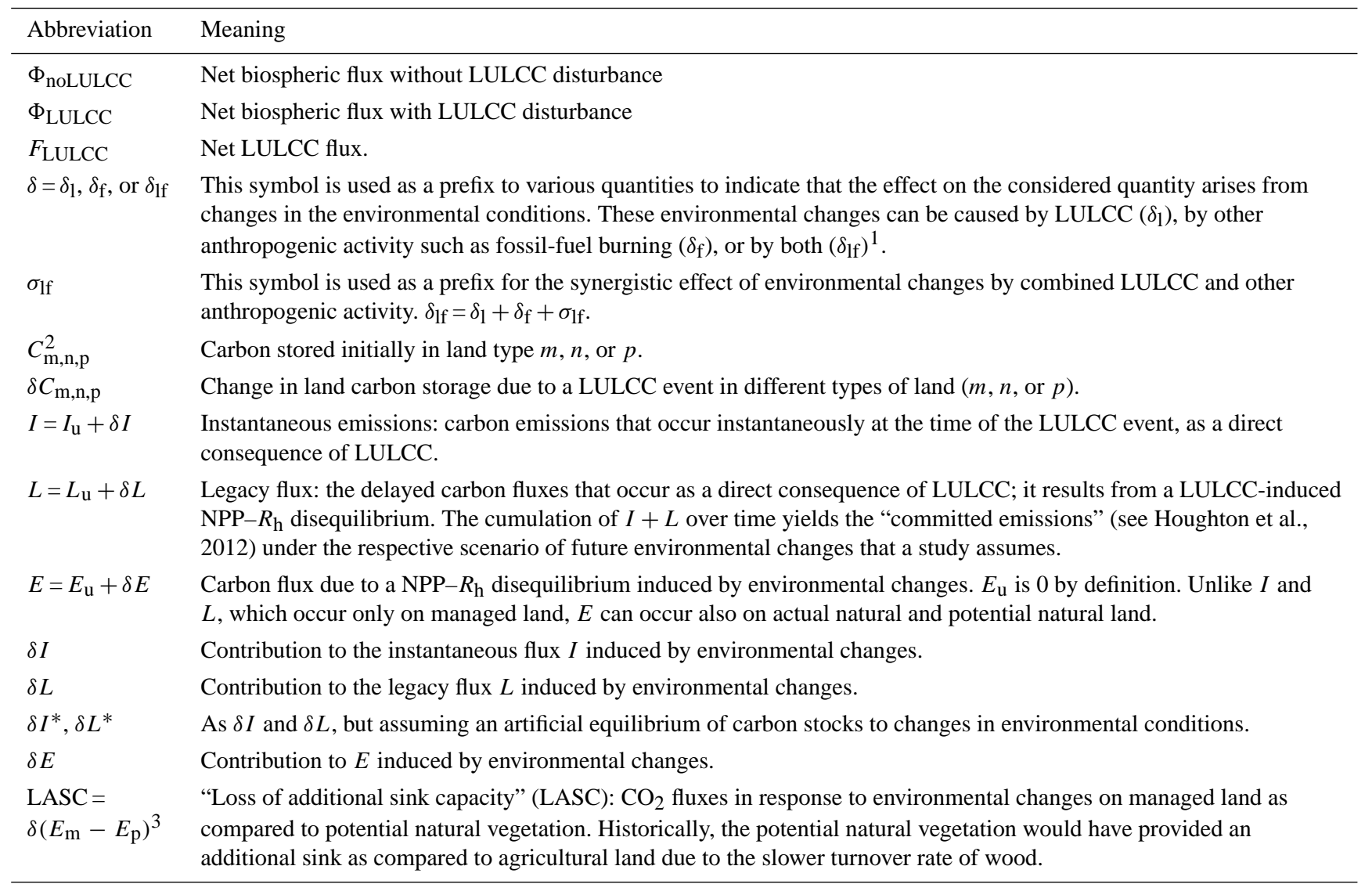

\footnotetext{
${ }^{1}$ We use " $\delta$ " without subscript as a general term to refer to any fluxes due to environmental changes, be they induced by LULCC (" $l$ "), by other external drivers such as fossil-fuel burning (" $f$ "), or a combination of both (" $f$ "). ${ }^{2}$ Note that for a sum of fluxes or stocks on different areas, such as " $E_{\mathrm{m}}+E_{\mathrm{n}}$ " we sometimes use the shorthand " $E_{\mathrm{mn}}$ ". ${ }^{3}$ Note that for effects of the same environmental changes on different fluxes we write e.g. $\delta\left(E_{\mathrm{m}}-E_{\mathrm{p}}\right)$ as shorthand for $\delta E_{\mathrm{m}}-\delta E_{\mathrm{p}}$.
}

different ways and on different timescales to environmental changes. Both NPP and $R_{\mathrm{h}}$ are influenced by environmental conditions, for example $\mathrm{CO}_{2}$ fertilization effects on NPP and dependence of soil respiration on temperature and moisture. Further, $R_{\mathrm{h}}$ also depends on NPP. Due to the slow turnover rates of many carbon stocks, $R_{\mathrm{h}}$ follows the evolution of NPP with a time lag. For example, an increase in NPP initially leads to a carbon sink (increase in NEP) as long as NPP and $R_{\mathrm{h}}$ are in disequilibrium.

Environmental changes may be induced by the effects of LULCC, or by other human activity, most notably the burning of fossil fuels. LULCC can therefore influence land carbon fluxes directly via anthropogenic changes in vegetation distribution and carbon stocks, and indirectly by altering environmental conditions. The latter is often referred to as "land use feedback" in modelling studies (Strassmann et al., 2008).

To summarize, the whole net biosphere flux following LULCC, including direct and indirect effects of LULCC and potential other changes due to environmental conditions, can be written as

$\Phi_{\text {LULCC }}=I+L+E$.

The component fluxes can occur on various types of land and under various environmental conditions. A minimal set of environmental conditions needed to distinguish different published methods comprises undisturbed environmental conditions (subscript "u"), LULCC-induced changes in environmental conditions ("l"), and other human-induced changes in environmental conditions, most notably due to fossil-fuel burning (thus labeled " $f$ "). A minimal set of land types needed to distinguish the different methods comprises managed land, including recovering areas (" $m$ "), actual natural land unaffected by direct LULCC activity (" $n$ "), and potential natural vegetation on managed land, which represents the same areas as managed land but assumes the vegetation were unaffected by LULCC (" $p$ ") (see Table 2 for detailed definitions). The potential natural vegetation is important for 
Table 2. Definitions of land types and environmental conditions needed to distinguish the different methods to estimate the net LULCC flux*.

\begin{tabular}{|c|c|c|}
\hline Subscript & Name & Definition \\
\hline \multicolumn{3}{|r|}{ (a) Environmental conditions } \\
\hline$u$ & $\begin{array}{l}\text { Undisturbed } \\
\text { environmental } \\
\text { conditions }\end{array}$ & $\begin{array}{l}\text { In many methods land fluxes are estimated assuming environmental conditions that are largely } \\
\text { unaffected by anthropogenic activity and exhibit no long-term trend (natural interannual variability } \\
\text { may be included). This usually refers to pre-industrial conditions. }\end{array}$ \\
\hline$l$ & $\begin{array}{l}\text { LULCC-induced } \\
\text { changes in } \\
\text { environmental } \\
\text { conditions }\end{array}$ & $\begin{array}{l}\text { Simulations account for changes in environmental conditions due to LULCC. The atmospheric } \mathrm{CO}_{2} \\
\text { concentration has increased by about } 20 \mathrm{ppm} \text { due to LULCC emissions, and climate is affected by both } \\
\text { biogeochemical and biogeophysical effects (Brovkin et al., 2004; Pongratz et al., 2010). }\end{array}$ \\
\hline$f$ & $\begin{array}{l}\text { Non-LULCC } \\
\text { ("fossil-fuel")- } \\
\text { induced changes } \\
\text { in environmental } \\
\text { conditions }\end{array}$ & $\begin{array}{l}\text { Simulations account for changes in environmental conditions due to all other (non-LULCC) } \\
\text { anthropogenic activity, predominantly due to fossil-fuel emissions causing a long-term upward trend in } \\
\text { atmospheric } \mathrm{CO}_{2} \text { concentration (by about } 80 \mathrm{ppm} \text { since pre-industrial times) and associated climate } \\
\text { change, but also potentially other effects such as nitrogen deposition (Denman et al., 2007). }\end{array}$ \\
\hline$\lambda$ & $\begin{array}{l}\text { Environmental } \\
\text { conditions for a } \\
\text { specific } \\
\text { simulation that } \\
\text { accounts for } \\
\text { LULCC }\end{array}$ & $\begin{array}{l}\text { In the case of ESM simulations, } \lambda \text { refer to environmental conditions that are influenced by LULCC } \\
\text { (cases } l \text { and } l f \text { ). } \\
\text { In the case of uncoupled DGVM simulations, } \lambda=\gamma=\text { either } u, l, f \text {, or } l f \text {. }\end{array}$ \\
\hline$\gamma$ & $\begin{array}{l}\text { Reference } \\
\text { environmental } \\
\text { conditions to } \lambda\end{array}$ & $\begin{array}{l}\text { In the case of ESM simulations, } \gamma \text { is the reference conditions, which refers to the environmental } \\
\text { conditions defined in } \lambda \text { but excluding the effects of LULCC (cases } u \text { and } f \text {, respectively). } \\
\text { In the case of uncoupled DGVM simulations, } \lambda=\gamma=\text { either } u, l, f \text {, or } l f \text {. }\end{array}$ \\
\hline$\sigma_{\mathrm{lf}}$ & $\begin{array}{l}\text { Synergy effects } \\
\text { of } l \text { and } f\end{array}$ & $\begin{array}{l}\text { Synergy effects on carbon fluxes when a combination of LULCC-induced }(l) \text { and other environmental } \\
\text { changes }(f) \text { occurs (see Sect. 2.6). }\end{array}$ \\
\hline
\end{tabular}

(b) Land types

Managed land

Areas of vegetation disturbed by direct LULCC activity. This includes actively managed areas under agricultural or forest management; these areas may be in disequilibrium due to recent LULCC, or may have reached a quasi-equilibrium in their managed state. It also includes abandoned areas, which have been managed at some point in the past but are no longer under management and are now recovering.

$n \quad$ Actual natural land

$p$
Areas actually under natural vegetation that have never been disturbed by direct LULCC activity, but also areas that have been abandoned from management sufficiently long ago so that they have fully recovered and are no longer distinguishable from undisturbed vegetation in terms of carbon stocks.

This is the natural vegetation cover that is assumed to occur on land areas if they were not under the actual managed land activity. It is a hypothetical assumption necessary to certain types of simulation setups. The land area with assumed $p$ in one setup (without LULCC) is identical to the area under $m$ in a comparative setup (with LULCC).

\footnotetext{
* Note that the distinction between managed and actual natural vegetation is often artificial as human impact can alter vegetation structure and species composition in subtle ways beyond those commonly classified as distinct by observation-based LULCC data sets. Often, natural vegetation will not fully recover due to ecosystem degradation; this effect is accounted for in some of the studies discussed here (e.g. Houghton et al., 1983). These effects are of secondary importance to our study, and the overly sharp distinction between actual natural and managed land is introduced here to highlight different assumptions made in published net LULCC flux estimates.
}

the without-LULCC simulation that is needed as a reference to quantify the human impact by LULCC as compared to a world without LULCC interference, and thus assumes the hypothetical land cover unaffected by man , " $p$ ", in lieu of " $m$ " (i.e. the with-LULCC simulation contains " $m n$ " as vegetation distribution, while the without-LULCC simulation contains " $p n$ " - obviously, $p$ and $n$ may be constituted by the same natural vegetation types, but they refer to different areas: those of managed land vs. those actually under natural vegetation).
We use the following subscripts to carbon fluxes: $m, n$, or $p$ indicates the type of land the flux belongs to; $u, f, l$, or lf indicates under which environmental conditions the flux occurs, where the latter $(l f)$ denotes the environmental conditions of $l$ and $f$ combined. Figure 1 uses the partitioning based on type of land and environmental conditions to further specify the flux components of Eq. (3) in the following. 

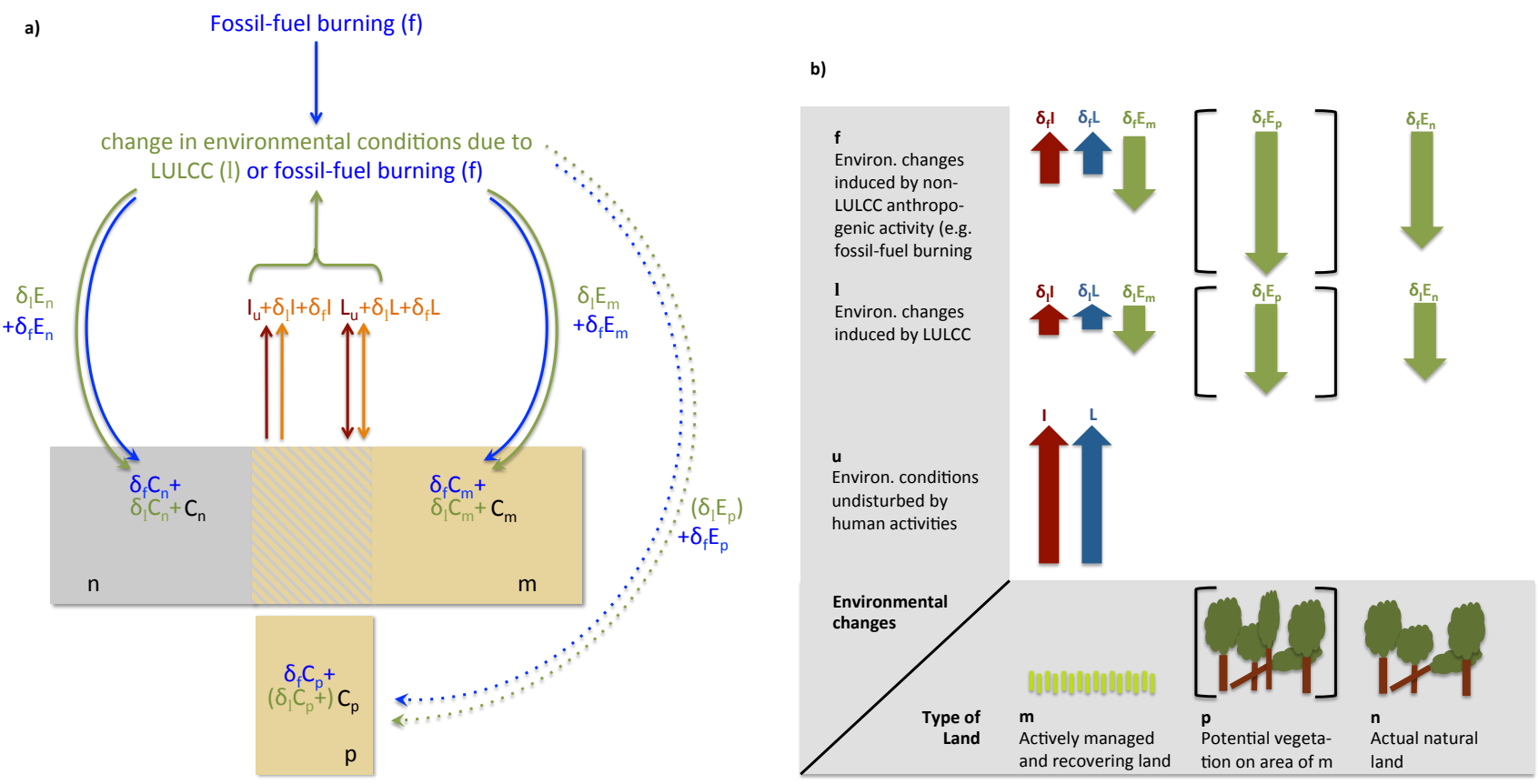

Fig. 1. Conceptual definition of land-atmosphere carbon fluxes representing all individual fluxes included in different model approaches to quantify the net LULCC flux. Note that no approach models every flux. (a) Illustration of the effects of LULCC and changing environmental conditions on carbon stocks and fluxes. Colours indicate steps in the causal chain set off by a LULCC event. Black: initial state. Dark red: effects of changes in vegetation distribution due to LULCC (dashed rectangle being transformed from actual natural to managed land) on carbon stocks ("direct LULCC effects"). Green: feedbacks of LULCC via environmental conditions on carbon stocks and fluxes. The LULCC feedback is put in parenthesis for potential natural vegetation because in coupled (ESM) simulations this flux will not occur due to the absence of LULCC; however, in uncoupled (DGVM) simulations the atmospheric $\mathrm{CO}_{2}$ concentration can be prescribed so as to include both LULCC and fossil-fuel effects, and $\delta_{1} E_{\mathrm{p}}$ occurs. Orange: subsequent changes in carbon fluxes from changes in vegetation due to LULCC-induced environmental changes ("indirect LULCC effects"). Blue: changes in carbon fluxes due to other externally induced environmental changes, primarily due to fossil-fuel burning. (b) Summary of carbon fluxes related to LULCC from (a), distinguished by the environmental conditions under which they occur $(u$ : undisturbed environmental conditions; $l$ : LULCC-induced changes in environmental conditions; $f$ : other externally induced changes in environmental conditions, primarily due to fossil-fuel burning) and by the vegetation state of the area the fluxes occur on ( $m$ : managed land; $n$ : actual natural land; $p$ : potential vegetation on the area of managed land). Note that in an individual model simulation, the vegetation state will be composed of either actual natural and managed land, when LULCC is accounted for, or actual natural and potential natural (instead of managed) land, when no LULCC is considered; because the net LULCC flux is derived as the difference between with- and without-LULCC simulations, fluxes on potential natural vegetation occur only as subtrahend, marked by square brackets here. $I$ : instantaneous emissions from LULCC, $L$ : legacy flux; $E$ : changes in carbon stocks as a response to environmental changes. $\delta_{\mathrm{u}}$ fluxes are 0 by definition and not depicted. Note that all fluxes apart from instantaneous emissions $(I)$ may act as a source or sink of carbon on land; the arrow directions indicated here loosely refer to historical evidence for global fluxes, but in fact depend on region, assumed scenario of LULCC and environmental conditions, and model.

\subsection{Direct effects of LULCC activity on carbon fluxes under undisturbed environmental conditions}

We start our considerations with two areas of actual natural and managed land in Fig. 1a ( $n$ : grey plus dashed rectangle; $m$ : beige rectangle) with a certain amount of carbon (indicated by $C_{\mathrm{n}}$ and $C_{\mathrm{m}}$ ). Direct effects of a LULCC event are considered, where a certain part of the area under natural vegetation (dashed in Fig. 1a) is transformed to managed land. As a results of this transformation, there is a release of instantaneous emissions to the atmosphere, and slower carbon stock changes occur that will be part of the legacy flux - including emissions as well as uptake in regrowing vegetation(dark red arrows in Fig. 1a). Note that, while we use the case of transformation of natural to managed land as an illustration in Fig. 1a, our considerations hold also for a change from one type of management to another and for recovery of managed land to a quasi-natural state.

If we assume, as the simplest base case, that the direct effects of LULCC occur under environmental conditions unaffected by human disturbance, then $I=I_{\mathrm{u}}, L=L_{\mathrm{u}}$, and $E=E_{\mathrm{u}}=0$, and Eq. (3) can be specified as

$\Phi_{\mathrm{LULCC}}=I_{\mathrm{u}}+L_{\mathrm{u}}+E_{\mathrm{u}}=I_{\mathrm{u}}+L_{\mathrm{u}}$.

We have dropped the term $E_{\mathrm{u}}\left(E_{\mathrm{u}}=0\right)$ because under environmental conditions undisturbed by human activity a 
disequilibrium of NPP and $R_{\mathrm{h}}$ arises only due to natural climate variability and natural long-term trends in climate. We can assume the effects of climate variability on NPP and $R_{\mathrm{h}}$ to largely cancel out on longer timescales. Natural longterm trends in climate are an order of magnitude smaller than human-induced trends over the centennial timescale on which LULCC has become significant (Forster et al., 2007).

\subsection{Carbon fluxes induced by the effects of changes in environmental conditions}

The carbon fluxes induced by LULCC under undisturbed environmental condition have to be complemented by additional fluxes when environmental conditions are altered. The impact of environmental change on carbon fluxes is represented by the term $\delta E$; the " $\delta$ " notation indicates that the additional terms come from changed environmental conditions that are due to LULCC (" $l$ ", green colour in Fig. 1a), due to other anthropogenic activity, predominantly fossil-fuel burning (" $f$ ", blue colour in Fig. 1a), or both. LULCC-induced environmental changes include both biogeophysical effects, such as changes in albedo, and biogeochemical effects, such as changes in atmospheric $\mathrm{CO}_{2}$. Environmental changes affect carbon stocks and fluxes on both managed $\left(\delta E_{\mathrm{m}}\right)$ and actual natural land $\left(\delta E_{\mathrm{n}}\right)$ (or, if simulated, on potential natural vegetation, $\delta E_{\mathrm{p}}$, and actual natural land) (see Fig. 1a).

With this in mind, we can write (knowing $E_{\mathrm{u}}=0$ ), for a simulation with managed or with potential natural vegetation, respectively,

$E=\delta E=\delta E_{\mathrm{mn}}$ or $E=\delta E=\delta E_{\mathrm{pn}}$.

It depends on the simulation setup whether environmental changes refer to LULCC-induced changes $(l)$, changes due to other anthropogenic activity $(f)$, or both $(l f)$. The Results section will show the various simulation setups used in publications and the corresponding terms contained in the flux $E$.

\subsection{Carbon fluxes arising from the combination of direct LULCC activity and effects of environmental changes}

The carbon fluxes of Sects. 2.2 and 2.3 have to be further complemented by the fluxes that arise due to the combined occurrence of direct LULCC effects and effects of environmental changes: the fluxes caused by environmental changes alter carbon stocks on land ( $\delta C$ terms in Fig. 1a). This implies that at the instance of a LULCC event such as deforestation, the amount of carbon available for emissions as $I$ and $L$ has been changed, and that carbon sources and sink terms in $L$ such as occur during plant regrowth also respond to the altered environmental conditions. Thus, $I_{\mathrm{u}}$ and $L_{\mathrm{u}}$ from above have to be complemented by fluxes $\delta I$ and $\delta L$, where again the change in environmental conditions may refer to $l, f$, or lf.
$I=I_{\mathrm{u}}+\delta I$

$L=L_{\mathrm{u}}+\delta L$

In our framework, the effects of environmental changes on instantaneous emissions, $\delta I$, and legacy flux, $\delta L$, are a consequence of the changes in environmental conditions and thus existence of the flux $\delta E$ prior to the LULCC event. For example, an increase in the atmospheric $\mathrm{CO}_{2}$ concentration has caused a flux $\delta E$ that has led to an increase of the standing forest biomass. This increased biomass leads to the additional emission terms $\delta I$ and $\delta L$ in case a LULCC event now occurs and clears this forest. The distinction between $\delta I+\delta L$ on the one hand and $\delta E$ on the other, both being attributable to the same type of change in environmental condition on the same land area ( $n$ transferred to $m$ ), may thus seem artificial. However, it is necessary because published studies may account for $\delta I$ and $\delta L$, but not $\delta E$, depending on how they account for environmental changes (see Sect.3): (1) environmental changes may be simulated in a transient way, which implies a NPP- $R_{\mathrm{h}}$ disequilibrium - in this case, fluxes $\delta I, \delta L$, and $\delta E$ are all explicitly simulated. (2) Environmental changes may be accounted for because observational data of carbon densities are used (as will be discussed in method B later). However, while observational data implicitly capture the current disequilibrium, observations are only a snapshot so that changes are not accounted for in a transient way; i.e. the snapshot state of environmentally altered carbon stocks is assumed to apply throughout the simulation - in this case, fluxes $\delta I, \delta L$, and $\delta E$ are simulated, but $\delta E$ fluxes are 0. (3) Environmental changes are simulated in a non-transient way by assuming they have changed as compared to conditions undisturbed by human activity, but that they have reached a new equilibrium state - in this case too, $\delta I$ and $\delta L$ are simulated (albeit overestimated by assuming an artificial equilibrium of higher carbon stocks due to $\mathrm{CO}_{2}$ fertilization applied throughout the historical period; see discussion of method D5), but because no NPP- $R_{\mathrm{h}}$ disequilibrium exists in this setup, $\delta E$ fluxes are not simulated.

In Fig. $1 \mathrm{a}$, the additional $\delta$ terms to $I_{\mathrm{u}}$ and $L_{\mathrm{u}}$ are indicated in orange. Carbon fluxes now form a closed feedback loop: an initial disturbance by a LULCC event leads to a carbon flux that alters environmental conditions, which feeds back on $E$ and carbon stocks, so that emissions of subsequent LULCC events are altered. To summarize, this feedback loop includes direct effects of LULCC $\left(I_{\mathrm{u}}\right.$ and $\left.L_{\mathrm{u}}\right)$, indirect effects of LULCC through environmental change $\left(\delta_{1} E\right)$, (indirect) effects of other anthropogenic-driven changes in environmental conditions $\left(\delta_{\mathrm{f}} E\right)$, and fluxes that arise because of the combined occurrence of direct and indirect effects of LULCC $\left(\delta_{1} I\right.$ and $\left.\delta_{1} L\right)$ or of direct effects of LULCC and effects of other anthropogenic changes in environmental conditions $\left(\delta_{\mathrm{f}} I\right.$ and $\left.\delta_{\mathrm{f}} L\right)$. 


\subsection{Potential vegetation and loss of additional sink capacity}

Forests have large amounts of woody biomass and typically have a slower average turnover rate than managed land cover types with which they may be replaced, e.g. pastureland and cropland. An increase in biomass due to $\mathrm{CO}_{2}$ fertilization would therefore be expected to lead to larger carbon stores and longer-term storage in forest than in non-woody managed vegetation. Thus, upon deforestation this possibility of surplus storage following an increase in atmospheric $\mathrm{CO}_{2}$ is lost and leads to a "loss of additional sink capacity" (LASC) and a higher calculated $F_{\text {LULCC }}$. To quantify the LASC, changes in NEP due to environmental changes have to be compared for managed land with a hypothetical situation where that particular land had not been converted, i.e. when it would be covered with "potential natural vegetation". Accordingly,

$\mathrm{LASC}=\delta\left(E_{\mathrm{m}}-E_{\mathrm{p}}\right)$.

The LASC is thus an effect of the combined occurrence of LULCC and environmental changes. The general effect of the LASC plays a role in the "net land use amplifier effect" quantified by Gitz and Ciais (2003) and the "replaced sources/sinks" quantified by Strassmann et al. (2008) (but the exact definitions of net land use amplifier effect, replaced sources/sinks, and LASC differ; see Pongratz et al., 2009b). Note that, while in future simulations this effect leads to a higher estimate of $F_{\text {LULCC }}$ due to increased carbon storage in potential natural vegetation as a result of the predominance of the $\mathrm{CO}_{2}$-fertilization effect, the process of comparing to a hypothetical situation could also lead to lower apparent LULCC fluxes, e.g. if the potential natural vegetation has lower biomass due to burning or negative climate impacts.

In Fig. 1a, the area of potential natural vegetation is the same as that of the land transformed to managed land in the LULCC event, and excludes the area of land that has already been under management at our initial state of consideration (or simulation). This reflects the setup of most of the modelling studies discussed in Sect. 3: without-LULCC simulations as well as the model spinup usually use the land use map of the reference year at which the simulations start (e.g. pre-industrial LULCC extent at 1850), not a global map of potential natural vegetation. Therefore, only the carbon fluxes caused by changes in LULCC following the reference year are simulated. If instead a global map of potential natural vegetation without any land use were used for withoutLULCC simulation and spinup, the LASC would occur on a larger area and be globally more significant. The choice of reference year (modelling studies referenced below start at $10000 \mathrm{BC}, 800,1700,1850 \mathrm{AD}$, and later) explains part of the differences between estimates of the net LULCC flux for those studies that include the LASC effect.

\subsection{Multiple feedbacks and linearity of fluxes}

Figure 1a illustrates that feedbacks of second order may occur in the coupled model system, as e.g. $\delta I$ and $\delta L$ in turn influence environmental conditions. Further, the NPP- $R_{\mathrm{h}}$ disequilibrium fluxes feed back on environmental conditions. This becomes relevant for the different vegetation distributions in with/without-LULCC simulations - because $\delta E_{\mathrm{m}}$ (of the with-LULCC simulation) and $\delta E_{\mathrm{p}}$ (of the withoutLULCC simulation) are different, environmental conditions will also differ to some extent between the two simulations. This has subsequent consequences on all other fluxes: for example, $\delta_{\mathrm{f}} E_{\mathrm{n}}$, although not dependent on LULCC directly or in any first-order feedback, will slightly differ in the with/without-LULCC cases. Such second-order effects occur only in the subset of methods that include feedbacks (namely, those using coupled ESMs; see Sect.3) and must be expected to be small compared to the first-order effects of LULCC.

Further non-linearities are introduced when a combination of LULCC-induced $(l)$ and other environmental changes $(f)$ occurs (all methods apart from E1, D1, and D2 below). For example, the effects of $\mathrm{CO}_{2}$ fertilization on plants tend to saturate at high levels, so that the sum of carbon uptake due to only LULCC-induced increases in atmospheric $\mathrm{CO}_{2}$ and due to only fossil-fuel-induced increases is larger than the response to the combined forcing, when the combined forcing approaches saturation levels. An opposite example may be when the combined effects lead to a crossing of an environmental threshold (e.g. tree-line temperature dependence, fire, or drought), which may not be reached when considering $l$ and $f$ alone. In simulations that include a combination of LULCC-induced and other environmental changes the $\delta_{\text {lf }}$ terms therefore include a synergy term, $\sigma_{\mathrm{lf}}\left(\delta_{\mathrm{lf}}=\delta_{1}+\delta_{\mathrm{f}}+\sigma_{\mathrm{lf}}.\right)$

Note that even for a single forcing ( $l$ alone or $f$ alone) the induced carbon fluxes may exhibit non-linearity, e.g. when the single forcing is sufficient to reach saturation levels or environmental thresholds. In our approach, the terms $\delta_{1}$ and $\delta_{\mathrm{f}}$ each contain this potential individual non-linearity (following Stein and Alpert, 1993).

\subsection{Derivation of the flux components for with/ without-LULCC simulations}

As stated earlier, the net LULCC flux is typically determined with respect to a reference state that excludes human land use activity (Eq. 2) by comparing the net biospheric flux from two simulations, one with LULCC ( $\left.\Phi_{\text {LULCC }}\right)$ and one without LULCC ( $\left.\Phi_{\text {noLULCC }}\right)$. All the fluxes and feedbacks illustrated in Fig. 1a and described in the sections above can be included in this framework, enabling us to compare specific model approaches and identify which fluxes are included in which approach (as presented in Sect. 3).

We introduce two new terms to represent the different environmental conditions between the with- and 
without-LULCC simulations, independent of whether they include other environmental changes $(f): \lambda$ refers to environmental conditions that are influenced by LULCC (cases $l$ and $l f) ; \gamma$ is the reference conditions, which refers to the same environmental conditions except that the effects of LULCC are excluded (if $\lambda=l$, then $\gamma=u$; if $\lambda=l f$, then $\gamma=f$; see Table 2). Thus $F_{\text {LULCC }}$ is the difference between reference environmental conditions on actual natural and potential natural land $\left(\Phi_{\mathrm{pn}, \gamma}\right)$, and environmental conditions including LULCC on actual natural and managed land $\left(\Phi_{\mathrm{mn}, \lambda}\right)$ :

$F_{\mathrm{LULCC}}=\Phi_{\mathrm{LULCC}}-\Phi_{\mathrm{noLULCC}}=\Phi_{\mathrm{mn}, \lambda}-\Phi_{\mathrm{pn}, \gamma}$.

Including an additional simulation $\Phi_{\mathrm{mn}, \gamma}$ (reference conditions on managed and actual natural land) enables a separation of the direct and indirect effects of LULCC, as done e.g. by Pongratz et al. (2009b). We thus extend Eq. (9) by subtracting and adding the same simulation:

$$
\begin{aligned}
F_{\mathrm{LULCC}} & =\Phi_{\mathrm{mn}, \lambda}-\Phi_{\mathrm{pn}, \gamma}=\underbrace{\Phi_{\mathrm{mn}, \lambda}-\Phi_{\mathrm{mn}, \gamma}}_{\text {indirect effects }} \\
& +\underbrace{\Phi_{\mathrm{mn}, \gamma}-\Phi_{\mathrm{pn}, \gamma}}_{\text {direct effects }} .
\end{aligned}
$$

The individual flux components can be derived for each of the simulations separately collecting the terms from Eqs. (4)-(7):

$$
\begin{aligned}
& \Phi_{\mathrm{mn}, \lambda}=I_{\mathrm{u}}+L_{\mathrm{u}}+\delta_{\lambda}\left(I+L+E_{\mathrm{m}}+E_{\mathrm{n}}\right) \\
& \Phi_{\mathrm{mn}, \gamma}=I_{\mathrm{u}}+L_{\mathrm{u}}+\delta_{\gamma}\left(I+L+E_{\mathrm{m}}+E_{\mathrm{n}}\right) \\
& \Phi_{\mathrm{pn}, \gamma}=\delta_{\gamma}\left(E_{\mathrm{p}}+E_{\mathrm{n}}\right) .
\end{aligned}
$$

The direct LULCC effects under given environmental conditions then are

$\Phi_{\mathrm{mn}, \gamma}-\Phi_{\mathrm{pn}, \gamma}=I_{\mathrm{u}}+L_{\mathrm{u}}+\delta_{\gamma}\left(I+L+\left(E_{\mathrm{m}}-E_{\mathrm{p}}\right)\right)$

and thus include

1. instantaneous emissions $\left(I_{\mathrm{u}}\right)$,

2. legacy flux $\left(L_{\mathrm{u}}\right)$,

3. potential additional effects of the reference environmental conditions on $I\left(\delta_{\gamma} I\right)$ and $L\left(\delta_{\gamma} L\right)$,

4. loss of additional sink capacity (LASC; $\left.\delta_{\gamma}\left(E_{\mathrm{m}}-E_{\mathrm{p}}\right)\right)$.

The indirect LULCC effects at the given (actual) vegetation distribution are (using $\delta_{\lambda}-\delta_{\gamma}=\delta_{1}+\sigma_{\mathrm{l} \gamma}$, where $\sigma_{\mathrm{lu}}=0$ and $\left.\delta_{\mathrm{u}}=0\right)$

$\Phi_{\mathrm{mn}, \lambda}-\Phi_{\mathrm{mn}, \gamma}=\left(\delta_{1}+\sigma_{\mathrm{l} \gamma}\right)\left(I+L+E_{\mathrm{m}}+E_{\mathrm{n}}\right)$

and thus include

1. fluxes due to the combined occurrence of direct and indirect LULCC effects $\left(\left(\delta_{1}+\sigma_{1 \gamma}\right) I\right.$ and $\left.\left(\delta_{1}+\sigma_{1 \gamma}\right) L\right)$,
2. other indirect LULCC effects $\left(\left(\delta_{1}+\sigma_{1 \gamma}\right) E_{\mathrm{m}}+\left(\delta_{1}+\right.\right.$ $\left.\left.\sigma_{\mathrm{l} \gamma}\right) E_{\mathrm{n}}\right)$.

Equations (12a) and (12b) are illustrative to discuss the various direct and indirect effects. However, most modelling studies will not perform the additional simulation $\Phi_{\mathrm{mn}, \gamma}$, but simulate LULCC effects directly from the coupled with/without-LULCC simulations (Eq. 9), which yields

$$
\begin{aligned}
\Phi_{\mathrm{mn}, \lambda}-\Phi_{\mathrm{pn}, \gamma} & =I_{\mathrm{u}}+L_{\mathrm{u}}+\delta_{\lambda}\left(I+L+E_{\mathrm{m}}+E_{\mathrm{n}}\right) \\
& -\delta_{\gamma}\left(E_{\mathrm{p}}+E_{\mathrm{n}}\right) .
\end{aligned}
$$

Equation (12a), (12b) and (12c) indicate all potential components (summarized in Fig. 1b), but not all occur for all simulation setups, as will become clear in the Results section when we apply these equations to the various published methods to quantify the net LULCC flux.

The previous paragraphs of Sect. 2.7 implicitly referred to the setup of coupled ESM simulations. The key difference to typical uncoupled DGVM setups lies in the assumptions on $\lambda$ and $\gamma$. In the ESM case, where $\lambda$ and $\gamma$ differ by the influence of LULCC on environmental conditions, the additional effect of $\gamma$ in Eq. (12a) refers only to effects of fossilfuel-induced environmental changes $(f)$. For DGVM simulations, however, we have to reconsider Eq. (9) and allow both with/without-LULCC simulation to use the same environmental conditions (i.e. in the uncoupled DGVM case, $\lambda=\gamma=u, l, f$, or $l f$ ). Then, Eq. (12a) may additionally include the indirect LULCC effects, and Eq. (12b) becomes 0 apart from potential synergistic terms.

\section{Results}

Reviewing studies using ESMs, uncoupled DGVMs, and bookkeeping models, we show in the following that as few as two component fluxes $\left(I_{\mathrm{u}}+L_{\mathrm{u}}\right)$ and as many as 10 of the 12 possible component fluxes of Eqs. (12a), (12b), and (12c) or Fig. 1 have been included in publications as part of the net LULCC flux, with a huge variety of constellations between these two extremes. Figure 2 compares the flux components included in each method.

\subsection{ESM simulations: coupled with/without-LULCC simulations including LULCC feedbacks}

We start our review with coupled ESM methods, which have the potential to include all carbon fluxes and feedbacks illustrated in Fig. 1a. The usual approach is to perform with/without-LULCC simulations in a coupled setup, although methods differ with respect to the reference environmental conditions $\gamma$, which may either include (E2) or not include (E1) fossil-fuel emissions. Replacing the generic terms in Eq. (10) with these two simulation setups, and knowing $E_{\mathrm{u}}=0$ (Sect. 2.3), yields the following: 


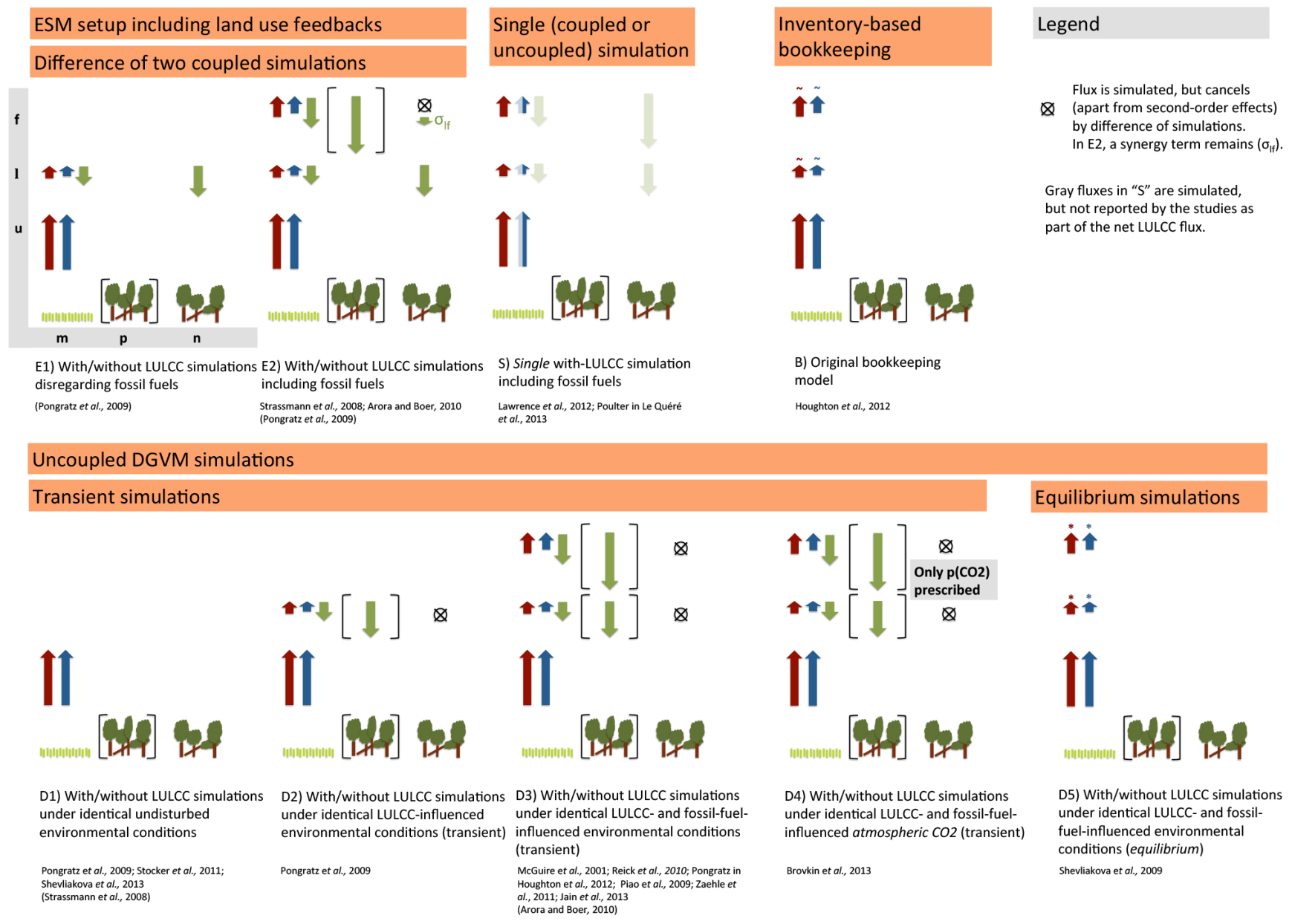

Fig. 2. Comparison of published methods to estimate the net LULCC flux with respect to flux components that are included or excluded. The complete set of flux components has been shown in Fig. 1b. Note that all simulations that account for the combined effects of LULCCinduced and other environmental changes $(l$ and $f)$ include synergy effects $\left(\delta_{\mathrm{lf}}=\delta_{1}+\delta_{\mathrm{f}}+\sigma_{\mathrm{lf}}\right.$; see Sect. 2.6); the f arrows are implicitly meant to include these synergies. Tilde and asterisk indicate that fluxes account for environmental changes, but not in a transient way: method B prescribes inventory-based carbon stocks as constant throughout the historical simulation; method D5 assumes the biosphere to be in equilibrium with present-day environmental changes throughout the historical simulation. References in parentheses indicate fluxes that were studied by the authors but not intended to represent their interpretation of the "net LULCC flux"; instead they were used to diagnose the influence of different approaches or flux terms, or to compare with other published studies.

E1. $\gamma$ does not account for fossil-fuel burning; i.e. $\gamma=u$ :

$$
\begin{aligned}
F_{\mathrm{LULCC}} & =\Phi_{\mathrm{mn}, 1}-\Phi_{\mathrm{mn}, \mathrm{u}}+\Phi_{\mathrm{mn}, \mathrm{u}}-\Phi_{\mathrm{pn}, \mathrm{u}} \\
& =\delta_{\mathrm{l}}\left(I+L+E_{\mathrm{m}}+E_{\mathrm{n}}\right)+I_{\mathrm{u}}+L_{\mathrm{u}}
\end{aligned} .
$$

This method has been used by Pongratz et al. (2009b) (Fig. 2). They performed the additional simulation $\Phi_{\mathrm{mn}, \mathrm{u}}$ to be able to distinguish between the direct effects of LULCC in the form of instantaneous emissions plus legacy flux on the one hand (called "primary emissions" in that publication) and the indirect feedback effects induced by the LULCC-induced environmental changes (called "coupling flux"). The resulting overall flux $\left(F_{\text {LULCC }}\right)$ was called "net anthropogenic land cover change emissions", but "primary emissions" $\left(I_{\mathrm{u}}+L_{\mathrm{u}}\right)$ was the term compared to other published net land use emission estimates.

E2. $\gamma$ accounts for fossil-fuel burning:

$$
\begin{aligned}
F_{\mathrm{LULCC}} & =\Phi_{\mathrm{mn}, \mathrm{lf}}-\Phi_{\mathrm{mn}, \mathrm{f}}+\Phi_{\mathrm{mn}, \mathrm{f}}-\Phi_{\mathrm{pn}, \mathrm{f}} \\
& =\left(\delta_{\mathrm{l}}+\sigma_{\mathrm{lf}}\right)\left(I+L+E_{\mathrm{m}}+E_{\mathrm{n}}\right)+I_{\mathrm{u}} \cdot(13 \mathrm{~b}) \\
& +L_{\mathrm{u}}+\delta_{\mathrm{f}}\left(I+L+\left(E_{\mathrm{m}}-E_{\mathrm{p}}\right)\right)
\end{aligned}
$$

Method E2 has been used by Strassmann et al. (2008), calling $F_{\text {LULCC }}$ "land use flux" or "net carbon emissions", and by Arora and Boer (2010), calling $F_{\text {LULCC }}$ "land use change emissions" or "net land use change flux". Unlike E1, this method includes, in the term $\delta_{\mathrm{f}} E_{\mathrm{m}}-\delta_{\mathrm{f}} E_{\mathrm{p}}$, the LASC due to fossil-fuel-induced changes in environmental conditions. 
The most prominent difference of both methods E1 and E2 over any of the following methods is that the net LULCC flux includes the carbon fluxes due to LULCC-induced environmental changes (land use feedback). They occur on both managed land $\left(\delta_{1} E_{\mathrm{m}}\right)$ and actual natural land $\left(\delta_{1} E_{\mathrm{n}}\right)$ and have, historically, caused a carbon sink (see Sect. 4).

\subsection{Uncoupled DGVM simulations}

Unlike the previous coupled ESM simulations, environmental conditions are uncoupled from vegetation processes in the DGVM setup, so that the same reference environmental conditions are used in both simulations. Therefore, Eq. (9) becomes

$F_{\mathrm{LULCC}}=\Phi_{\mathrm{mn}, \gamma}-\Phi_{\mathrm{pn}, \gamma}$.

Note that, while the coupled approach that accounts for LULCC always represents transient environmental conditions, the uncoupled approach can also prescribe constant environmental conditions (undisturbed by human activity, or constant at a disturbed point in time). Uncoupled simulations are often inconsistent: a static vegetation distribution may be used together with environmental changes that account for LULCC effects, or vice versa.

We again distinguish published methods by the type of reference environmental conditions:

D1. $\gamma$ represents undisturbed, constant environmental conditions $(u)$ :

$$
F_{\mathrm{LULCC}}=\Phi_{\mathrm{mn}, \mathrm{u}}-\Phi_{\mathrm{pn}, \mathrm{u}}=I_{\mathrm{u}}+L_{\mathrm{u}} .
$$

This method yields the "bookkeeping flux" by Strassmann et al. (2008) and Shevliakova et al. (2013) and the "primary emissions" by Pongratz et al. (2009b) (see method E1) and Stocker et al. (2011). Note that these simulations prescribe climate corresponding to the pre-industrial era (1700 or $800 \mathrm{AD})$, which is indeed largely undisturbed by human activity, although some effects of LULCC on environmental conditions may have occurred by this time (Ruddiman, 2003; Pongratz et al., 2009b).

D2. $\gamma$ represents transiently changing environmental conditions influenced by LULCC $(l)$ :

$$
\begin{aligned}
F_{\mathrm{LULCC}} & =\Phi_{\mathrm{mn}, 1}-\Phi_{\mathrm{pn}, 1}=I_{\mathrm{u}}+L_{\mathrm{u}} \\
& +\delta_{1}\left(I+L+\left(E_{\mathrm{m}}-E_{\mathrm{p}}\right)\right) .
\end{aligned}
$$

Note that in this setup the LASC is induced by LULCC effects (unlike the LASC induced by fossil-fuel burning in method E2). This method is not commonly used (simulations have been performed by Pongratz et al. (2009b) to isolate the LASC due to LULCCinduced environmental changes); like the other uncoupled approaches it assumes an inconsistent set of
LULCC and environmental conditions (potential natural vegetation linked with environmental changes influenced by LULCC), but further depends on environmental conditions $(l)$ that are not directly observable in this isolated form today (but can be obtained from ESM simulations).

D3. $\gamma$ represents transiently changing environmental conditions influenced by both LULCC and other anthropogenic activity $(l f)$ :

$$
\begin{aligned}
F_{\mathrm{LULCC}} & =\Phi_{\mathrm{mn}, \mathrm{lf}}-\Phi_{\mathrm{pn}, \mathrm{lf}}=I_{\mathrm{u}}+L_{\mathrm{u}} \\
& +\delta_{\mathrm{lf}}\left(I+L+\left(E_{\mathrm{m}}-E_{\mathrm{p}}\right)\right) .
\end{aligned}
$$

This widely used method was introduced in the model intercomparison simulation protocol by McGuire et al. (2001) with the resulting flux called "release in net carbon storage associated with cropland establishment and abandonment". It has also been quantified by Pongratz in Houghton et al. (2012) as "net land use flux LUC $+\mathrm{CO}_{2}$ "; by Piao et al. (2009) as "land use change emissions"; by Reick et al. (2010) as "anthropogenic land cover change emissions"; by Arora and Boer (2010) as "land use change emissions when with and without LUC simulations see same atmospheric $\mathrm{CO}_{2}$ "; by Zaehle et al. (2011) as "net carbon loss from land-cover changes"; by Jain et al. (2013) as "net LULUC emissions"; and as "emissions from land use, land-use change and forestry $\left(E_{\mathrm{LUC}}\right)$ " in recent multi-model DGVM simulations (Le Quéré et al., 2014; here, the reference simulation equated to the "residual terrestrial sink"). Note that the studies by Zaehle et al. (2011) and by Jain et al. (2013) also include the nitrogen cycle and transient effects of $\mathrm{N}_{2} \mathrm{O}$ emissions.

D4. $\gamma$ represents transiently changing environmental conditions influenced by both LULCC and fossil-fuel burning; different to method D3, however, only the atmospheric $\mathrm{CO}_{2}$ conditions are prescribed as identical in the with/without-LULCC simulations (indicated here by "If_CO2"), while the other environmental conditions are simulated interactively and thus differ between the two simulations:

$$
\begin{aligned}
& F_{\mathrm{LULCC}}=\Phi_{\mathrm{mn}, \mathrm{lf} \_\mathrm{CO} 2}-\Phi_{\mathrm{pn}, \mathrm{lf} \_\mathrm{CO} 2} \\
& =I_{\mathrm{u}}+L_{\mathrm{u}}+\delta_{\mathrm{lf}_{-} \mathrm{CO} 2}\left(I+L+\left(E_{\mathrm{m}}-E_{\mathrm{p}}\right)\right) .
\end{aligned}
$$

This method has been applied in the LUCID-CMIP5 study (Brovkin et al., 2013) to quantify LULCCinduced changes in carbon stocks across a range of models for two scenarios of future LULCC and climate. This method is a hybrid between uncoupled DGVM and coupled ESM simulations: the atmospheric $\mathrm{CO}_{2}$ concentration is derived from the transient scenarios of the representative concentration 
pathways (RCP), which account for LULCC emissions as well as fossil-fuel emissions. In both withand without-LULCC simulations the atmospheric $\mathrm{CO}_{2}$ concentration seen by the terrestrial biosphere (and relevant for climate) is identical, as is typical of uncoupled DGVM simulations. However, because environmental conditions other than the atmospheric $\mathrm{CO}_{2}$ concentration, most notably climate, are simulated in a coupled way typical of ESMs, they differ between the with- and without-LULCC simulations by the (non$\mathrm{CO}_{2}$-related) influence of LULCC; that is, the biogeophysical effects of LULCC influence climate in the with-LULCC but not in the without-LULCC simulation. Therefore, the land use feedback is taken into account in the D4 method and could be represented as in method E2, but it occurs only for biogeophysical effects. The land use feedback on global carbon fluxes via the biogeophysical effects, however, is of secondary importance to the land use feedback via the atmospheric $\mathrm{CO}_{2}$ concentration and has been simulated in one model to cancel on the global scale (Pongratz et al., 2009a).

D5. $\gamma$ represents present-day environmental conditions ("If_today"); simulations are equilibrium simulations:

$$
\begin{aligned}
F_{\text {LULCC }} & =\Phi_{\text {mn,lf_today }}-\Phi_{\text {pn,lf_today }} \\
& =I_{\mathrm{u}}+L_{\mathrm{u}}+\delta_{\text {lf_today }}\left(I^{*}+L^{*}\right) .
\end{aligned}
$$

This approach has been used by Shevliakova et al. (2009) (note that the without-LULCC reference simulation is only performed implicitly). In this study, lf_today are recent environmental conditions including interannual variability cycled in a quasi-equilibrium. Unlike in realistic transient simulations, LASC is not accounted for because equilibrium simulations do not simulate a NPP- $R_{\mathrm{h}}$ disequilibrium (i.e. $E=0$ ). However, the effect of today's environmental changes on direct emissions and legacy fluxes is accounted for $\left(\delta_{\mathrm{lf}} I\right.$ and $\delta_{\text {If }} L$ ). This also reveals two slight inconsistencies: first, LULCC, even if it occurs far back in the past, acts on biomass stocks under today's environmental conditions. Second, these biomass stocks are unrealistically assumed to be in equilibrium with today's transiently changing climate (indicated by ${ }^{*}$ above). Because the NPP- $R_{\mathrm{h}}$ disequilibrium currently causes a carbon sink, simulating carbon stocks to an artificial equilibrium state likely leads to an overestimate of carbon stocks in natural vegetation and thus to an overestimate of LULCC-induced emissions.

\subsection{Single (coupled or uncoupled) LULCC simulation}

This method performs one single with-LULCC simulation, either in a coupled ESM setup or an uncoupled DGVM setup.
No reference simulation is performed, which allows only an incomplete subset of fluxes to be quantified.

$F_{\text {LULCC }}=\Phi_{\text {LULCC }}=\Phi_{\mathrm{mn}, \lambda}$

This method can be applied to environmental conditions including and excluding non-LULCC activity such as fossilfuel burning, but only the first method is found in the literature:

S. $\gamma$ accounts for fossil-fuel burning:

$$
\begin{gathered}
F_{\mathrm{LULCC}}=\Phi_{\mathrm{mn}, \mathrm{lf}}=I_{\mathrm{u}}+L_{\mathrm{u}}+\delta_{\mathrm{lf}} \\
\left(I+L+E_{\mathrm{m}}+E_{\mathrm{n}}\right) .
\end{gathered}
$$

These are the same terms as in E1 except that the indirect effects account for environmental changes due to both LULCC and fossil-fuel burning at once. This method has been used by Lawrence et al. (2012) as "land use flux", and in a similar way by Poulter et al. in Le Quéré et al. (2013) as "emissions from landuse change". However, both studies report only instantaneous emissions and product pool fluxes, i.e. $I$ components and a part of the $L$ components of above equation, not the $E$ components. Referring only to product pool changes, the $L$ components in the study by Lawrence et al. (2012) ignore fluxes related to regrowth or decomposition of on-site organic matter; the implications of this are discussed in Sect. 4.3.

\subsection{Inventory-based bookkeeping model}

The original, inventory-based bookkeeping models calculate carbon fluxes for the direct effects of LULCC based on changes in land use area combined with observation-based parameter estimates of the carbon density and growth and decay rates of carbon pools for specific vegetation types in different regions. Unlike in ESM and DGVM studies, the without-LULCC reference simulation is performed only implicitly: when an area is transformed from one vegetation type to another, the carbon loss or gain is determined by the difference between the two vegetation types' observationbased parameters. The observational data are taken from inventories or remote sensing and are thus derived from one specific time period. This implies that they do not account for transient changes and that the reference environmental conditions are those at the time of the inventory ( $\gamma \_$inventory):

$$
\begin{aligned}
F_{\mathrm{LULCC}} & =\Phi_{\mathrm{mn}, \gamma}-\Phi_{\mathrm{pn}, \gamma}=\Phi_{\mathrm{mn}, \gamma_{-} \text {inventory }} \\
& -\Phi_{\mathrm{pn}, \gamma_{-} \text {inventory }} .
\end{aligned}
$$

Because inventories are performed under actual environmental conditions influenced by both LULCC and other anthropogenic activity, only one choice exists for $\gamma$ $\left(\gamma=l f \_\right.$inventory). 
B.

$$
\begin{aligned}
F_{\text {LULCC }} & =\Phi_{\mathrm{mn}, 1 \mathrm{f} \_ \text {inventory }}-\Phi_{\mathrm{pn}, \mathrm{ff} \_ \text {inventory }} \\
& =I_{\mathrm{u}}+L_{\mathrm{u}}+\delta_{\mathrm{If} \_ \text {inventory }} \\
& \left(I+L+\left(E_{\mathrm{m}}-E_{\mathrm{p}}\right)\right)
\end{aligned}
$$

This means that the resulting equation for this method is similar to Eq. 14e derived for present-day equilibrium simulations with DGVMs (D5). However, two key differences exist: first, in the bookkeeping approach, carbon stocks are not assumed to be in an artificial equilibrium, and, second, they refer not necessarily to today but to the (often older) time period of the inventory.

The $\mathrm{LASC}_{\mathrm{lf} \_ \text {inventory }}=\delta_{\mathrm{lf} \_ \text {inventory }}\left(E_{\mathrm{m}}-E_{\mathrm{p}}\right)=0$ arises because observed carbon stocks are not in equilibrium; it is 0 , however, because method B does not account for changes in environmental conditions after the inventory has been made and thus $\delta_{\text {lf_inventory }} E_{\mathrm{m}}=\delta_{\mathrm{lf} \_ \text {inventory }} E_{\mathrm{p}}=0$ (see Sect. 2.4). The effect of changes in environmental conditions on carbon stocks are instead captured by the $\delta_{\text {If_inventory }} I$ and $\delta_{\text {lf_inventory }} L$ terms.

This method has been introduced by Houghton et al. (1983). Several recent estimates of the net LULCC flux apply a version of Houghton's bookeeping scheme (Achard et al., 2004; DeFries et al., 2002; Houghton, 2010; Reick et al., 2010; Baccini et al., 2012; Pan et al., 2011; Le Quéré et al., 2013). Carbon densities vary across studies but are all based on a range of inventories. The inventories often rely on data from the 1970s or earlier and thus capture only part of presentday human disturbance (with the notable exception of Baccini et al. (2012), which uses satellite data to estimate biomass carbon density). Similar to D5, the $\delta$ fluxes based on recent inventories under environmental change are considered to be representative throughout the historical past despite the fact that environmental changes were very small prior to the 20th century.

While most of the published estimates of the net LULCC flux fall clearly in one of the nine terminological categories above, a few special cases exist where methods from different types of models have been combined. The Introduction discussed how some bookkeeping approaches modify fixed carbon densities to account for the effect of environmental changes that is generally represented by process-based models. A combination of two approaches has been used by Kato et al. (2011, 2013), who complemented the S method in transient simulations accounting for LULCC and fossil fuels by estimates of regrowth fluxes based on a modified bookkeeping approach that accounts for environmental changes.

\section{Discussion}

Our review of the multitude of methods to estimate the net LULCC flux reveals three key differences: the inclusion or exclusion of indirect effects of LULCC (also called land use feedback); accounting for the loss of additional sink capacity; and full accounting of legacy fluxes.

\subsection{Key difference 1: land use feedback}

The key difference of coupled ESM simulations with/without LULCC (E1, E2) to all other methods is the inclusion of the land use feedback $\delta_{1} E$ (the effect of emissions from LULCC on land carbon storage via higher concentrations of atmospheric $\mathrm{CO}_{2}$ and other environmental changes). The land use feedback on managed land, $\delta_{1} E_{\mathrm{m}}$, is taken into account in some of the uncoupled DGVM methods (D2-4), but is calculated as part of the LASC (see next section). In the ESM simulations, by contrast, it is included as additional carbon sink. A larger discrepancy between methods, however, stems from the inclusion of the land use feedback on actual natural land $\left(\delta_{1} E_{\mathrm{n}}\right)$, which includes highly productive vegetation, such as tropical rainforest. This indirect effect of LULCC is captured by the ESMs but cancels out in the DGVM simulations.

Three studies have quantified the strength of the land use feedback on actual natural and managed land (Strassmann et al., 2008; Pongratz et al., 2009b; Arora and Boer, 2010), finding that it is a sink equivalent to about $25-50 \%$ of the net LULCC flux that excludes these feedbacks (Fig. 3, Table 3). Studies including the land use feedback $\delta_{1} E$ find a net LULCC flux about half that of earlier studies (which excluded the feedback) (Arora and Boer, 2010). The largest difference is expected to stem from the land use feedback on actual natural land, which was included in the net LULCC flux estimate of Arora and Boer (2010).

The land use feedback reflects genuine changes in atmospheric $\mathrm{CO}_{2}$ concentration as a result of human activity on the land, and as such should be quantified for full carbon accounting. The question becomes whether it should be accounted as part of the net LULCC flux (as it is indirectly a result of LULCC even though it affects all land, including unmanaged lands), as done in method E1 and E2; this definition, however, conflicts with the majority of scientific studies and the approach taken in policy (IPCC, 2006; Denman et al., 2007). Alternatively, the net LULCC flux can be defined so as to include only the feedback on managed land, while the feedback on unmanaged lands is counted as part of the residual terrestrial flux, as done by methods D2-4 as part of the LASC. Finally, the net LULCC flux can also be defined so as to account only for fluxes associated with direct effects of human activity (i.e. $I$ and $L$, possibly also the terms $\delta I$ and $\delta L)$ and to account for feedbacks as the residual terrestrial flux, as done by all other methods reviewed here. 
Table 3. Key processes that explain the largest differences between various estimates of the net LULCC flux. LASC is loss of additional sink capacity.

\begin{tabular}{|c|c|c|}
\hline Process & $\begin{array}{l}\text { Change in net LULCC flux if } \\
\text { process were accounted for }\end{array}$ & Reference \\
\hline Land use feedback & -25 to $-50 \%$ historically & Strassmann et al. (2008); Pongratz et al. (2009b); Arora and Boer (2010) ${ }^{1}$ \\
\hline LASC & $\begin{array}{l}\text { Less than }+10 \% \text { historically, up to } \\
+105 \% \text { by } 2100 \text { (for SRES A2 } \\
\text { scenario) }\end{array}$ & $\begin{array}{l}\text { Strassmann et al. (2008) (historical and future); Pongratz et al. }(2009 b)^{2} \text { and } \\
\text { Gasser and Ciais (2013) (historical) }\end{array}$ \\
\hline $\begin{array}{l}\text { Exclusion of } \\
\text { regrowth and } \\
\text { on-site legacy } \\
\text { flux }\end{array}$ & $\begin{array}{l}\text { Within reported range historically, } \\
\text { but } 256 \text { PgC as compared to } 25-62 \\
\text { PgC } 2006-2100 \text { (RCP 8.5), i.e. }+300 \\
\text { to } 900 \%\end{array}$ & Lawrence et al. (2012) compared to Brovkin et al. $(2013)^{3}$ \\
\hline
\end{tabular}

1 The three studies used different setups to quantify the land use feedback; see caption to Fig. 3 for details. ${ }^{2}$ Pongratz, in Houghton et al. (2012), estimates that the net LULCC flux quantified by method D3 is $8 \%$ larger than quantified by method D1, which is a result of counteracting effects: carbon sinks on managed land due to $\mathrm{CO}_{2}$ fertilization are overwhelmed by the non-realized higher carbon sinks on potential vegetation (i.e. LASC), and by higher instantaneous emissions and legacy flux. Estimates in Strassmann et al. (2008) refer to the bookkeeping vs. replaced sources/sinks (their Table 3). ${ }^{3}$ Estimates for Lawrence et al. (2012) refer to their Table 4 "land use"; this is exclusive of wood harvest, which makes this estimate better comparable to Brovkin et al. (2013) (their Table 4), because all models apart from the outlier MPI-ESM exclude wood harvest.

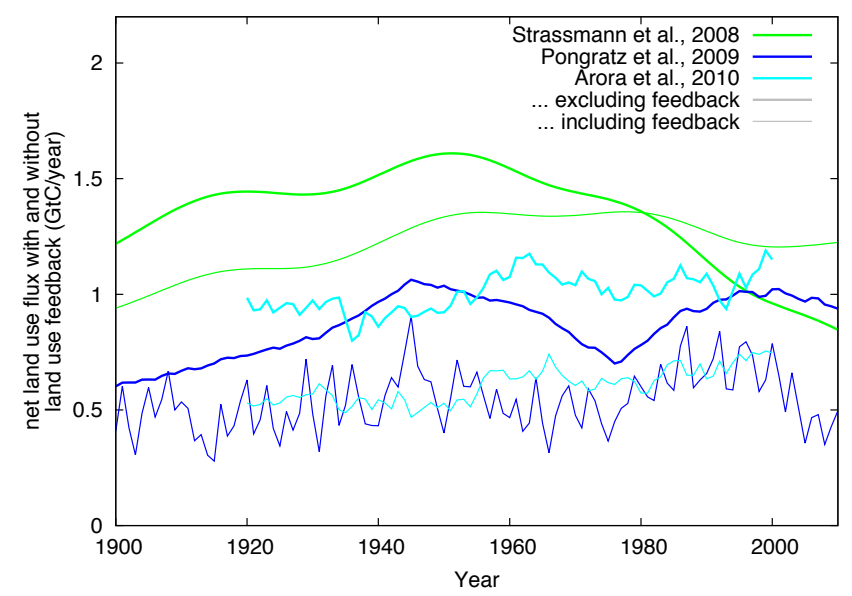

Fig. 3. Net LULCC fluxes including (thin lines) and excluding (thick lines) the land use feedback from Strassmann et al. (2008), Pongratz et al. (2009b), and Arora and Boer (2010) ${ }^{1}$. The land use feedback is of the order of $25 \%$ for Strassmann et al. (2008) and of $50 \%$ for Pongratz et al. (2009b) and Arora and Boer (2010) of the net LULCC flux excluding the land use feedback. ${ }^{1}$ The following methods were used in the individual studies: for the flux excluding the land use feedback: D1 (uncoupled DGVM simulations under undisturbed environmental conditions) by Strassmann et al. (2008) and Pongratz et al. (2009b), and D3 (uncoupled DGVM simulations under transiently changing environmental conditions influenced by both LULCC and fossil-fuel burning) by Arora and Boer (2010). For the LULCC flux including the land use feedback: E1 (ESM simulations not accounting for fossil-fuel burning) by Pongratz et al. (2009b), and E2 (ESM simulations accounting for fossil-fuel burning) by Strassmann et al. (2008) and Arora and Boer (2010). Difference of the methods (as can be derived from Results section or Fig. 2) yields the exact flux components.
The question becomes even more complicated considering practical limitations such as that the terms arising from a combination of LULCC-induced and other environmental changes cannot be attributed to just one or the other forcing, that many model setups do not allow for isolating the indirect effects of LULCC from the (indirect) effects of fossil-fuel burning (e.g. because they prescribe the atmospheric $\mathrm{CO}_{2}$ concentration to include effects of LULCC and fossil-fuel burning combined, as methods D3-5 do), or that computational considerations limit the number of simulations that can be performed to isolate flux components.

\subsection{Key difference 2: loss of additional sink capacity}

The LASC is accounted for whenever environmental conditions are changing over time and their effects on carbon fluxes from managed land are different from those on potential vegetation (i.e. with/without-LULCC simulations). The LASC is thus included in the uncoupled DGVM methods with transient changes in environmental conditions (D2-4) and in the ESM simulations that include fossil-fuel burning (E2) (see Fig. 2). However, the LASC is included in these methods to different extents: as a response to changes in environmental conditions induced by only LULCC (D2), by only fossil-fuel burning (E2), or by both (D3-4). In these methods, the net LULCC flux usually also comprises the effect of environmental changes on instantaneous emissions and legacy fluxes.

Strassmann et al. (2008, their Table 3), Pongratz et al. (2009b, their Table 2), and Gasser and Ciais (2013, their Fig. 2) agree in that the LASC and effects of environmental changes on instantaneous emissions and legacy flux historically amount to less than $10 \%$ (4-17 Gt carbon) as compared to the net LULCC flux with no feedbacks $\left(\mathrm{I}_{u}+\mathrm{L}_{u}\right)$ (their respective D1 quantification) (Table 3). However, Strassmann et al. have simulated that these effects will be the dominant 
term of net LULCC flux for future scenarios - roughly doubling estimated future net land use emissions if included in calculations. It needs to be noted, however, that the LASC depends strongly on processes such as $\mathrm{CO}_{2}$ fertilization that are not well understood, and on the assumed scenario. Strassmann et al. (2008) assume a scenario of continued clearing and very large environmental changes in particular due to fossil-fuel burning. Smaller environmental changes and afforestation will reduce the LASC.

Despite its potential future importance, it has not been discussed much in literature whether the LASC should be accounted for. The LASC is an unrealized flux, a lost sink instead of actual emissions, not reflected in any real change in atmospheric $\mathrm{CO}_{2}$ concentration. However, it shows up in the budget of atmospheric $\mathrm{CO}_{2}$ compared to a reference world without LULCC (often approximated by the late preindustrial era) reflecting the overall impact that land use change has had (or will have). If the net LULCC flux is chosen to be defined so as to include the LASC, the modelling protocol for spinup and reference simulation becomes particularly important: as discussed in Sect. 2.5, the simulated strength of the LASC is larger when the simulations for model spinup and for the reference without-LULCC case are done with potential natural vegetation as opposed to a map representative e.g. of the late pre-industrial era that includes substantial areas under land use already.

\subsection{Key difference 3: regrowth and on-site legacy flux}

The study by Lawrence et al. (2012) differs from all other methods in that it reports only a part of the legacy flux - the changes in product pools - thereby missing processes such as respiration of on-site residues, recovery of living vegetation, and adjustment of dead carbon stocks. It most notably excludes NEP changes due to regrowth of vegetation. With their "land use flux" of $119 \mathrm{PgC}$ plus wood harvest of about $64 \mathrm{PgC}$ emitted historically since 1850 , their net LULCC flux estimate is within the (wide) range of previous estimates. They are, however, substantially larger than other estimates for the future time periods, e.g. the LUCID-CMIP5 study that investigated the same scenarios (Brovkin et al., 2013). Missing the NEP-related carbon sink in regrowth, even the scenario of strong afforestation (RCP 6.0) leads to emissions larger than in the historical period. For scenarios RCP 2.6 and 8.5 this method yields a "land use flux" that is about 4-10 times larger compared to the majority of the LUCIDCMIP5 models (exclusive one outlier) (Table 3).

\subsection{Consistency with observable fluxes?}

None of the net LULCC flux quantifications identified in the published literature quantifies a flux that would be observable on the local or global scale. Site-based measurements of flux or stock change in lands subject to land use (management) or land use change would capture all fluxes shown over managed land in Fig. 1 (minus product pool changes that may occur off-site). However, methods E2 and D2-D4 account for the non-realized LASC effects; methods E1 and D1-2 ignore all or part of the environmental changes; and methods B and D5 assume present-day conditions to have prevailed throughout history. Method S as described in Eq. (15a) could capture all observable fluxes over managed land; however, those flux components actually reported by the studies performing a single simulation account only for a part of the legacy flux. This discrepancy between the flux observed and the individual flux components that models simulate may be one of the largest obstacles in reducing uncertainties resulting from modelling assumptions.

Comparison of site-based observations to model simulations may also be hampered by the fact that not all ESMs and DGVMs track carbon fluxes separately for actual natural and managed land. While most models allow for tracking carbon fluxes separately for different vegetation types (e.g. forest vs. cropland), they often lump together actual natural and managed/recovering areas within a vegetation type (e.g. lump together unmanaged and managed/recovering forest within a grid cell) to calculate carbon fluxes.

Difficulties in reconciling observational and modelling data may also stem from differences in accounting period. In certain regions, a large part of the observed terrestrial carbon sink may indeed be the result of the legacy flux rather than indirect environmental changes; i.e. the sink seen in many managed forests today is due to past land use or management changes such as afforestation. In particular in Europe, China, and the eastern US large areas under agricultural and forest management have been abandoned, sometimes more than a century ago. This leads to carbon sinks primarily due to the legacy flux up until today, but is difficult to disentangle from environmental effects (Erb et al., 2013). This is particularly true if information on historical LULCC is not available or the starting date of model simulations is too recent.

\subsection{Handling of indirect effects}

A recent publication (Houghton, 2013) argues that indirect effects of environmental changes should be kept separate from the direct effects of LULCC activity for political considerations, for lowering the uncertainty of the net LULCC flux, and for consistency in explanatory mechanism (direct LULCC effects are structural, while indirect effects are metabolic). Reporting and accounting for Annex I countries under the Kyoto Protocol attempts to give credit or debit for activities that are a direct result of human activity and thus to "factor out" indirect environmental effects (IPCC, 2013). This aims at avoiding credits for e.g. land sinks due to fossilfuel emissions by reporting on carbon stock changes in managed lands only. However, even in managed forests there are sinks due to environmental changes, and due to legacy effects from past management. For the second commitment period, it has become mandatory to report on managed forests using 
reference level accounting in an attempt to factor out past activity and indirect effects from activity since $1990^{1}$. In reference level accounting a projection of forest growth is made based on previous management and environmental effects (using methods from simple trend analysis through to forest growth models that either do or do not include climate and $\mathrm{CO}_{2}$ effects), and only deviations from this reference level attributable to management changes can be accounted for. In reality it is difficult to separate direct and indirect fluxes (Cowie et al., 2007) due to the use of observational data from ecosystems that have already been affected by environmental change, and due to the model set-ups.

Our study illustrates that a decision for excluding indirect effects, or including only specific flux components, will face major obstacles in its implementation. First, observational data available as model inputs or for model validation implicitly include direct and indirect effects. Second, many of the methods reviewed here are not able to isolate and exclude all of the component fluxes induced by indirect effects due to their specific modelling setup (including Houghton's bookkeeping approach, but see also Cowie et al., 2007). Third, a clear definition is required to identify which of the flux components count towards the "indirect effects": environmental changes can be (1) induced by LULCC (land use feedback) or by fossil-fuel emissions; (2) can induce changes in NPP- $R_{\mathrm{h}}$ disequilibrium fluxes either on managed land $\left(\delta_{1} E_{\mathrm{m}}, \delta_{\mathrm{f}} E_{\mathrm{m}}\right)$ - often compared to potential vegetation (i.e. $\left.\delta_{\mathrm{l}}\left(E_{\mathrm{m}}-E_{\mathrm{p}}\right), \delta_{\mathrm{f}}\left(E_{\mathrm{m}}-E_{\mathrm{p}}\right)\right)$ - or on actual natural vegetation $\left(\delta_{1} E_{\mathrm{n}}, \delta_{\mathrm{f}} E_{\mathrm{n}}\right)$; and (3) can alter instantaneous emissions and legacy fluxes $\left(\delta_{1} I, \delta_{1} L, \delta_{\mathrm{f}} I \delta_{\mathrm{f}} L\right)$. All of these fluxes can be counted towards the indirect effects.

Because the residual terrestrial sink is determined from the difference between the net land-atmosphere flux and the net LULCC flux (Eq. 1), the particular fluxes included in the residual sink will depend on the ones included in the net LULCC flux. For example, when the net LULCC flux is from the bookkeeping approach (Le Quéré et al., 2013), the residual flux refers to fluxes $\delta_{1} E_{\mathrm{m}}+\delta_{\mathrm{f}} E_{\mathrm{m}}+\delta_{1} E_{\mathrm{n}}+\delta_{\mathrm{f}} E_{\mathrm{n}}$ (plus additional fluxes caused by other unknown processes). However, up to three of these four fluxes are included in the net LULCC flux in the majority of other published estimates based on ESMs and DGVMs (Fig. 2). Thus, when DGVM results are used independently to infer the residual terrestrial flux (e.g. Le Quéré et al., 2013; Le Quéré, 2010) (runs with transient $\mathrm{CO}_{2}$ and climate but without LULCC), some indirect effects are counted twice. Furthermore, even fluxes on actual natural vegetation have been included in the net LULCC flux by some studies (method E1-2) if related to LULCC-induced environmental changes.

Even if consistently the same model is used to derive the components of the carbon budget, so that no double-counting

\footnotetext{
${ }^{1}$ Since the Durban Conference of Parties in 2011. See Decision 2/CMP.7: http://unfccc.int/resource/docs/2011/cmp7/eng/ 10a01.pdf
}

occurs, the choice of definition for the net LULCC flux determines the definition of the residual sink (Gasser and Ciais, 2013). For example, in the recent study by Shevliakova et al. (2013), method D1 has been used for the net LULCC flux, and this estimate has been subtracted from the net landatmosphere flux of a coupled ESM simulation accounting for LULCC and fossil-fuel burning; in this case, the resulting residual sink includes the additional instantaneous and legacy emissions of LULCC induced by environmental changes, $\delta_{\text {If }} I$ and $\delta_{\text {lf }} L$, which is not in line with other estimates of the residual sink (e.g. Le Quéré et al., 2014).

Our study highlights the importance of a common way to account for indirect effects: two of the three key differences in terminology identified here refer to indirect effects (land use feedback and LASC); but even studies that agree on excluding or including land use feedback or LASC differ in most cases with respect to the assumed environmental changes ( $u, l$, or $f$ in Fig. 2). So far, agreement has only been that indirect effects induced by fossil-fuel burning on actual natural vegetation $\left(\delta_{\mathrm{f}} E_{\mathrm{n}}\right)$ are not part of the net LULCC flux. Our study identifies and discusses the multitude of possibilities for defining the net LULCC flux in scientific research. However, the choice of definition, in particular the handling of indirect effects, is a political choice rather than a scientific one.

\subsection{Relevance for studies combining net LULCC flux estimates of multiple definitions}

Beyond its relevance for the definition of the residual terrestrial flux, the exact definition of the net LULCC flux becomes particularly important when estimates from several studies applying different methods are combined in one synthesis. Houghton et al. (2012) explicitly discussed the particular treatment of environmental changes as one reason for the large spread of the net LULCC flux estimates, and indeed the 13 referenced data sets used 4 different definitions (methods B, D1, D3, D5; Fig. 2 indicates the choice of method for each reference). Similar differences exist between the 5 net LULCC flux estimates used in the quantification of the global carbon budget by Le Quéré et al. (2013) (B, D1, D3, S, and a combination of $\mathrm{B}$ and $\mathrm{S}$ ). Based on such experiences, it is plausible to assume that the estimates reported for the Coupled Model Intercomparison Project 5 (CMIP5) as "net carbon mass flux into atmosphere due to land use change" face a similar divergence in terms of definitions applied.

Terminological differences also occurred during the development stage of the four scenarios for future anthropogenic emissions and climate for the IPCC Fifth Assessment Report produced by four integrated assessment models (IAMs). The IAM models estimated change in land cover and management in accordance with economic assumptions, but also quantified $\mathrm{CO}_{2}$ emissions from LULCC. These quantifications were needed by some of the ESMs included in the CMIP5 comparison that did not endogenously calculate the 
net LULCC flux and thus needed to prescribe LULCC emissions from the IAMs in the same way as fossil-fuel emissions were prescribed. Two of the four IAMs, GCAM and MESSAGE, followed an approach identical or similar to Houghton's bookkeeping method using observation-based growth parameters (method B in our study). The other two models, IMAGE and AIM, diagnosed the net LULCC flux from a single transient LULCC simulation (method $\mathrm{S}$ in our study) and included the effect of changing atmospheric $\mathrm{CO}_{2}$ on instantaneous and legacy emissions. In order to diagnose the LULCC fluxes beyond instantaneous emissions without comparing to a without-LULCC reference simulation, each of the two models had a different approach to calculating the legacy fluxes, including regrowth: the estimates by AIM used the VISIT vegetation model to simulate natural vegetation and soil carbon under changing $\mathrm{CO}_{2}$, determining not only gross deforestation fluxes but also rates of regrowth; the latter were used in a bookkeeping-type approach to track fluxes of regrowth following abandonment (see Sect. 3.4; Kato et al., 2011, 2013). The IMAGE model by contrast attributed all carbon fluxes on the abandoned field occurring in the first 25 years after the LULCC event to the net LULCC flux, while to natural vegetation after that time period (Klein Goldewijk et al., 1994; D. van Vuuren, personal communication, 2014). Despite this discrepancy in methods, all four scenarios were harmonized to a common value of the net LULCC flux in 2005 (it needs to be noted, however, that differences between the 4 IAMs due to different processes represented by the models and differences in input data led to differences in net LULCC flux estimates that are at least as large as terminological differences; see Meinshausen et al., 2011). To achieve a continuous time series of past and future LULCC emissions, the IAM data were further harmonized with the historical net LULCC flux by adjusting Houghton's bookkeeping estimates to match the present-day fluxes as simulated by the IAMs (e.g. Jones et al., 2011).

A framework like the one provided by our study can in the future serve as a reference to identify up front which components of the net LULCC flux (and the residual sink) will be quantified by an agreed model setup. It may thus, for a given scientific question, contribute to a convergence of methodology and therefore a reduction in the uncertainty of the most uncertain components of the global carbon budget.

\section{Conclusions}

The net LULCC flux, independent of its exact definition, is not observable at the global scale, but must be inferred with the help of models. As models make different assumptions and rely on different data sets, they cannot necessarily be expected to yield the same results. Such differences in methods together with uncertainties in extent of LULCC cause an uncertainty of about $50 \%$ around the decadal mean value (Houghton et al., 2012). Some of these uncertainties will be reduced with better availability of data from satellites and inventories.

While we will not be able to fully eliminate uncertainties due to model differences, a large source of confusion can be attributed to inconsistent definitions of what the net LULCC flux actually consists of. Here, we have shown that simply because of terminological differences, model estimates differ by a factor of 2 for the historical period. (Table 3). Estimates for future scenarios will likely be affected even more (a factor of 4-10 difference has been found, although this range includes model differences as well). Eliminating terminological differences will thus greatly reduce the large uncertainty range currently put on the net LULCC flux.

The publications reviewed in this study provided at least nine different definitions of the net LULCC flux and differ in particular with respect to accounting for the land use feedback, the loss of additional sink capacity, and of regrowth and on-site legacy fluxes. The choice of definition depends on the scientific or policy question (e.g. whether or not unrealized carbon fluxes are of interest; whether the interest is in full carbon accounting or accounting for direct human activity).

Unlike intrinsic uncertainties in data availability, process understanding and model parameterizations, terminological differences can be largely eliminated by careful choice and declaration of the component fluxes to be included in net LULCC flux estimates. As a wealth of new estimates of the net LULCC flux are being compiled e.g. in the framework of the IPCC's Fifth Assessment Report, it is particularly important at this point in time to understand the different approaches and their terminologies so that in comparing and understanding model results and their implications for climate policy we can identify and address the real uncertainties in carbon flux estimates.

Acknowledgements. We thank Kuno Strassmann, Vivek Arora, and Thomas Gasser for providing their estimates of net LULCC flux components; Pierre Friedlingstein, Ben Poulter, Etsushi Kato, Allison Thomson, Kees Klein Goldewijk, Detlef van Vuuren, and Georg Kindermann for helpful discussions; and Chris Jones, Thomas Gasser, and Vivek Arora for their helpful reviews. J. House was funded by a Leverhulme Research Fellowship. J. Pongratz was supported by the German Research Foundation's Emmy Noether Program (PO 1751/1-1). Collaboration between the authors was supported by COST Action ES0804 "The Terrestrial Biosphere in the Earth System" (TERRABITES).

Edited by: A. Kleidon 


\section{References}

Achard, F., Eva, H. D., Mayaux, P., Stibig, H.-J., and Belward, A.: Improved estimates of net carbon emissions from land cover change in the tropics for the 1990s, Global Biogeochem. Cy., 18, GB2008, doi:10.1029/2003GB002142, 2004.

Arora, V. K. and Boer, G. J.: Uncertainties in the 20th century carbon budget associated with land use change, Global Change Biol., 16, 3327-3348, 2010.

Baccini, A., Goetz, S. J., Walker, W. S., Laporte, N. T., Sun, M., Sulla-Menashe, D., Hackler, J., Beck, P. S. A., Dubayah, R., Friedl, M. A., Samanta, S., and Houghton, R. A.: Estimated carbon dioxide emissions from tropical deforestation improved by carbon-density maps, Nat. Clim. Change, 2, 182-185, 2012.

Brovkin, V., Sitch, S., von Bloh, W., Claussen, M., Bauer, E., and Cramer, W.: Role of land cover changes for atmospheric $\mathrm{CO}_{2}$ increase and climate change during the last 150 years, Global Change Biol., 10, 1253-1266, doi:10.1111/j.13652486.2004.00812.x, 2004.

Brovkin, V., Boysen, L., Arora, V., Boisier, J.-P., Cadule, P., Chini, L. P., Claussen, M., Friedlingstein, P., Gayler, V., van den Hurk, B. J. J. M., Hurtt, G., Jones, C. D., Kato, E., de Noblet-Ducoudre, N., Pacifico, F., Pongratz, J., and Weiss, M.: Effect of anthropogenic land-use and land cover changes on climate and land carbon storage in CMIP5 projections for the 21 st century, J. Climate, 26, 6859-6881, 2013.

Cowie, A. L., Kirschbaum, M. U. F., and Ward, M.: Options for including all lands in a future greenhouse gas accounting framework, Environ. Sci. Policy, 10, 306-321, 2007.

DeFries, R. S., Houghton, R. A., Hansen, M. C., Field, C. B., Skole, D., and Townshend, J.: Carbon emissions from tropical deforestation and regrowth based on satellite observations for the 1980s and 1990s, P. Natl. Acad. Sci., 99, 14256-14261, 2002.

Denman, K. L., Brasseur, G., Chidthaisong, A., Ciais, P., Cox, P. M. Dickinson, R. E., Hauglustaine, D., Heinze, C., Holland, E., Jacob, D., Lohmann, U., Ramachandran, S., da Silva Dias, P. L., Wofsy, S. C., and Zhang, X.: Couplings Between Changes in the Climate System and Biogeochmistry, in: Climat Change 2007: The Physical Science Basis, Contribution of Workin Group I to the Fourth Assessment Report of the Intergovernmental Panel on Climate Change, edited by: Solomon, S., Qin, D., Manning, M., Chen, Z., Marquis, M., Averyt, K. B., Tignor, M., and Miller, H. L., Cambridge University Press, Cambridge, UK and New Yori, NY, USA, 2007.

Erb, K., Kastner, T., Luyssaert, S., Houghton, R. A., Kuemmerle, T., Olofsson, P., and Haberl, H.: Bias in the attribution of forest carbon sinks, Nat. Clim. Change, 3, 854-856, 2013.

FAO: FAOSTAT Emissions database http://faostat3.fao. org/faostat-gateway/go/to/download/G2/*/E, last access: 1 June 2013.

Forster, P., Ramaswamy, V., Artaxo, P., Berntsen, T., Betts, R., Fahey, D. W., Haywood, J., Lean, J., Lowe, D. C., Myrhe, G., Nganga, J., Prinn, R., Raga, G., Schulz, M., and Van Dorland, R.: Changes in Atmospheric Constituents and in the Radiative Forcing, in: Climat Change 2007: The Physical Science Basis, Contribution of Working Group I to the Fourth Assessment Report of the Intergovernmental Panel on Climate Change, edited by: Solomon, S., Qin, D., Manning, M., Chen, Z., Marquis, M., Averyt, K. B., Tignor, M., and Miller, H. L., Cambridge University Press, Cambridge, UK and New York, NY, USA, 2007.
Gasser, T. and Ciais, P.: A theoretical framework for the net landto-atmosphere $\mathrm{CO}_{2}$ flux and its implications in the definition of "emissions from land-use change", Earth Syst. Dynam., 4, 171186, doi:10.5194/esd-4-171-2013, 2013.

Gitz, V. and Ciais, P.: Amplifying effects of land-use change on future atmospheric $\mathrm{CO}_{2}$ levels, Global Biogeochem. Cy., 17, 10241039, 2003.

Harris, N. L., Brown, S., Hagen, S. C., Saatchi, S. S., Petrova, S., Salas, W., Hansen, M. C., Potapov, P. V., and Lotsch, A.: Baseline map of carbon emissions from deforestation in tropical regions, Science, 336, 1573-1576, 2012.

Houghton, R. A.: How well do we know the flux of $\mathrm{CO}_{2}$ from landuse change?, Tellus B, 62, 337-351, 2010.

Houghton, R. A.: Keeping management effects separate from environmental effects in terrestrial carbon accounting, Global Change Biol., 19, 2609-2612, 2013.

Houghton, R. A., Hobbie, J. E., Melillo, J. M., Moore, B., Peterson, B. J., Shaver, G. R., and Woodwell, G. M.: Changes in the carbon content of terrestrial biota and soils between 1860 and 1980: A net release of $\mathrm{CO}_{2}$ to the atmosphere. Ecol. Monogr., 53, 235262, 1983.

Houghton, R. A., House, J. I., Pongratz, J., van der Werf, G. R., DeFries, R. S., Hansen, M. C., Le Quéré, C., and Ramankutty, N.: Carbon emissions from land use and land-cover change, Biogeosciences, 9, 5125-5142, doi:10.5194/bg-9-5125-2012, 2012.

IPCC: IPCC Guidelines for National Greenhouse Gas Inventories, Institute for Global Environmental Strategies (IGES), Japan, 2006.

IPCC: Revised Supplementary Methods and Good Practice Guidance Arising from the Kyoto Protocol (KP Supplement), Institute for Global Environmental Strategies (IGES), Japan, 2013.

Jain, A. K., Meiyappan, P., Song, Y., and House, J. I.: $\mathrm{CO}_{2}$ emissions from land-use change affected more by nitrogen cycle, than by the choice of land cover data, Global Change Biol., 19, 28932906, doi:10.1111/gcb.12207, 2013.

Jones, C. D., Hughes, J. K., Bellouin, N., Hardiman, S. C., Jones, G. S., Knight, J., Liddicoat, S., O’Connor, F. M., Andres, R. J., Bell, C., Boo, K.-O., Bozzo, A., Butchart, N., Cadule, P., Corbin, K. D., Doutriaux-Boucher, M., Friedlingstein, P., Gornall, J., Gray, L., Halloran, P. R., Hurtt, G., Ingram, W. J., Lamarque, J.-F., Law, R. M., Meinshausen, M., Osprey, S., Palin, E. J., Parsons Chini, L., Raddatz, T., Sanderson, M. G., Sellar, A. A., Schurer, A., Valdes, P., Wood, N., Woodward, S., Yoshioka, M., and Zerroukat, M.: The HadGEM2-ES implementation of CMIP5 centennial simulations, Geosci. Model Dev., 4, 543-570, doi:10.5194/gmd-4-543-2011, 2011.

Kato, E., Kawamiya, M., Kinoshita, T., and Ito, A.: Development of spatially explicit emission scenario from land-use change and biomass burning for the input data of climate projection, Proced. Environ. Sci., 6, 146-152, 2011.

Kato, E., Kinoshita, T., Ito, A., Kawamiya, M., and Yamagata, Y.: Evaluation of spatially explicit emission scenario of land-use change and biomass burning using a process-based biogeochemical model, J. Land Use Sci., 8, 104-122, 2013.

Klein Goldewijk, K., van Minnen, J. G., Kreileman, G. J. J., Vloedbeld, M., and Leemans, R.: Simulating the carbon flux between the terrestrial environment and the atmosphere, Water Air Soil Poll., 76, 199-230, 1994. 
Lawrence, P. J., Feddema, J. J., Bonan, G. B., Meehl, G. A., O’Neill, B. C., Oleson, K. W., Levis, S., Lawrence, D. M., Kluzek, E., Lindsay, K., and Thornton, P. E.: Simulating the biogeochemical and biogeophysical impacts of transient land cover change and wood harvest in the community climate system model (ccsm4) from 1850 to 2100, J. Climate, 25, 3071-3095, 2012.

Le Quéré, C.: Trends in the land and ocean carbon uptake, Curr. Opinon. Environ. Sustain., 2, 219-224, 2010.

Le Quéré, C., Andres, R. J., Boden, T., Conway, T., Houghton, R. A., House, J. I., Marland, G., Peters, G. P., van der Werf, G. R., Ahlström, A., Andrew, R. M., Bopp, L., Canadell, J. G., Ciais, P., Doney, S. C., Enright, C., Friedlingstein, P., Huntingford, C., Jain, A. K., Jourdain, C., Kato, E., Keeling, R. F., Klein Goldewijk, K., Levis, S., Levy, P., Lomas, M., Poulter, B., Raupach, M. R., Schwinger, J., Sitch, S., Stocker, B. D., Viovy, N., Zaehle, S., and Zeng, N.: The global carbon budget 1959-2011, Earth Syst. Sci. Data, 5, 165-185, doi:10.5194/essd-5-165-2013, 2013a.

Le Quéré, C., Peters, G. P., Andres, R. J., Andrew, R. M., Boden, T., Ciais, P., Friedlingstein, P., Houghton, R. A., Marland, G., Moriarty, R., Sitch, S., Tans, P., Arneth, A., Arvanitis, A., Bakker, D. C. E., Bopp, L., Canadell, J. G., Chini, L. P., Doney, S. C., Harper, A., Harris, I., House, J. I., Jain, A. K., Jones, S. D., Kato, E., Keeling, R. F., Klein Goldewijk, K., Körtzinger, A., Koven, C., Lefèvre, N., Omar, A., Ono, T., Park, G.-H., Pfeil, B., Poulter, B., Raupach, M. R., Regnier, P., Rödenbeck, C., Saito, S., Schwinger, J., Segschneider, J., Stocker, B. D., Tilbrook, B., van Heuven, S., Viovy, N., Wanninkhof, R., Wiltshire, A., Zaehle, S., and Yue, C.: Global carbon budget 2013, Earth Syst. Sci. Data Discuss., 6, 689-760, doi:10.5194/essdd-6-689-2013, 2013 b.

McGuire, A. D., Sitch, S., Clein, J. S., Dargaville, R., Esser, G., Foley, J., Heimann, M., Joos, F., Kaplan, J., Kicklighter, D. W., Meier, R. A., Melillo, J. M., Moore II, B., Prentice, I. C., Ramankutty, N., Reichenau, T., Schloss, A., Tian, H., Williams, L. J., and Wittenberg, U.: Carbon balance of the terrestrial biosphere in the twentieth century: Analyses of $\mathrm{CO}_{2}$, climate and land use effects with four process-based ecosystem models, Global Biogeochem. Cy., 15, 183-206, 2001.

Meinshausen, M., Smith, S. J., Calvin, K., Daniel, J. S., Kainuma, M. L. T., Lamarque, J.-F., Matsumoto, K., Montzka, S. A., Raper, S. C. B., Riahi, K., Thomson, A., Velders, G. J. M., and van Vuuren, D. P. P.: The RCP greenhouse gas concentrations and their extensions from 1765 to 2300, Climatic Change, 109, 213-241, 2011.

Pan, Y., Birdsey, R. A., Fang, J., Houghton, R., Kauppi, P. E., Kurz, W. A., Phillips, O. L., Shvidenko, A., Lewis, S. L., Canadell, J. G., Ciais, P., Jackson, R. B., Pacala, S. W., McGuire, A. D., Piao, S., Rautiainen, A., Sitch, S., and Hayes, D.: A large and persistent carbon sink in the worlds forests, Science, 333, 988-993, 2011.

Piao, S., Ciais, P., Friedlingstein, P., de Noblet-Ducoudre, N., Cadule, P., Viovy, N., and Wang, T.: Spatiotemporal patterns of terrestrial carbon cycle during the 20th century, Global Biogeochem. Cy., 23, GB4026, doi:10.1029/2008GB003339, 2009.
Piao, S., Sitch, S., Ciais, P., Friedlingstein, P., Peylin, P., Wang, X., Ahlström, A., Anav, A., Canadell, J. G., Cong, N., Huntingford, C., Jung, M., Levis, S., Levy, P. E., Li, J., Lin, X., Lomas, M. R., Lu, M., Luo, Y., Ma, Y., Myneni, R. B., Poulter, B., Sun, Z., Wang, T., Viovy, N., Zaehle, S., and Zeng, N.: Evaluation of terrestrial carbon cycle models for their response to climate variability and to $\mathrm{CO}_{2}$ trends, Global Change Biol., 19, 2117 2132, 2013.

Pongratz, J.: A model estimate on the effect of anthropogenic land cover change on the climate of the last millennium, Reports Earth Syst. Sci., 56, 1-136, 2009a.

Pongratz, J., Reick, C. H., Raddatz, T., and Claussen, M.: Effects of anthropogenic land cover change on the carbon cycle of the last millennium. Global Biogeochem. Cy., 23, GB4001, doi:10.1029/2009GB003488, 2009b.

Pongratz, J., Reick, C. H., Raddatz, T., and Claussen, M.: Biogeophysical versus biogeochemical climate response to historical anthropogenic land cover change, Geophys. Res. Lett., 37, L08702, doi:10.1029/2010GL043010, 2010.

Poulter, B., Hattermann, F., Hawkins, E., Zaehle, S., Sitch, S., Restrepo-Coupe, N., Heyder, U., and Cramer, W.: Robust dynamics of Amazon dieback to climate change with perturbed ecosystem model parameters, Global Change Biol., 16, 24762495, doi:10.1111/j.1365-2486.2009.02157.x, 2010.

Reick, C. H., Raddatz, T., Pongratz, J., and Claussen, M.: Contribution of anthropogenic land cover change emissions to pre-industrial atmospheric $\mathrm{CO}_{2}$, Tellus $\mathrm{B}, 62,329-336$, doi:10.1111/j.1600-0889.2010.00479.x, 2010.

Ruddiman, W.: The anthropogenic greenhouse era began thousands of years ago, Climatic Change, 61, 261-293, 2003.

Shevliakova, E., Pacala, S. W., Malyshev, S., Hurtt, G. C., Milly, P. C. D., Caspersen, J. P., Sentman, L. T., Fisk, J. P., Wirth, C., and Crevoisier, C.: Carbon cycling under 300 years of land use change: Importance of the secondary vegetation sink, Global Biogeochem. Cy., 23, GB2022, doi:10.1029/2007GB003176, 2009.

Shevliakova, E., Stouffer, R. J., Malyshev, S., Krasting, J. P., Hurtt, G. C., and Pacala, S. W.: Historical warming reduced due to enhanced land carbon uptake, P. Natl. Acad. Sci., 110, 16730 16735, 2013.

Stein, U. and Alpert, P.: Factor separation in numerical simulations, J. Atmos. Sci., 50, 2107-2115, 1993.

Stocker, B. D., Strassmann, K., and Joos, F.: Sensitivity of Holocene atmospheric $\mathrm{CO}_{2}$ and the modern carbon budget to early human land use: analyses with a process-based model, Biogeosciences, 8, 69-88, doi:10.5194/bg-8-69-2011, 2011.

Strassmann, K. M., Joos, F., and Fischer, G.: Simulating effects of land use changes on carbon fluxes: past contributions to atmospheric $\mathrm{CO}_{2}$ increases and future commitments due to losses of terrestrial sink capacity, Tellus B, 60, 583-603, 2008.

Zaehle, S., Ciais, P., Friend, A. D., and Prieur, V.: Carbon benefits of anthropogenic reactive nitrogen offset by nitrous oxide emissions, Nat. Geosci., 4, 601-605, 2011. 